\title{
User Perceptions of Aesthetic Visual Design Variables within the Informing Environment: A Web-Based Experiment
}

\author{
Daniel Peak, Victor Prybutok, Michael Gibson, and \\ Yu "Andy" Wu \\ University of North Texas, Denton, TX, USA \\ daniel.peak@unt.edu; victor.prybutok@unt.edu; \\ michael.gibson@unt.edu; andy.wu@unt.edu

\begin{abstract}
Chenyan Xu
Richard Stockton College of New Jersey, Galloway, NJ, USA

chenyan.xu@stockton.edu
\end{abstract}

\begin{abstract}
A person's psychological and physiological characteristics influence both behavior and decisionmaking in the informing process, such that system designers should understand users to reduce biases and misinformation. Given the substantial influence that visual interfaces have on users, system designers can benefit from understanding both the visual and functional aspects of interface design. To address these issues, this study employs the visual system design (VSD) framework, which integrates a rich and varied collection of visual design variables and IS (Information Systems) variables. This study performs a visual web-based experiment with data collected from 105 participants, where results show that changes in aesthetic elements of interface design, specifically, visual value and color, do ripple across a transition zone between visual design and IS variables. Both participants with and without visual design training were able to perceive those changes as intended. This study provides preliminary support to the VSD framework. It also suggests that bias and randomness are reduced in the informing process if system interfaces are designed with mindful and skilled use of design and aesthetic elements.
\end{abstract}

Keywords: Aesthetic visual design, IS development, human-computer interaction, experiment, transdisciplinary

Material published as part of this publication, either on-line or in print, is copyrighted by the Informing Science Institute. Permission to make digital or paper copy of part or all of these works for personal or classroom use is granted without fee provided that the copies are not made or distributed for profit or commercial advantage AND that copies 1) bear this notice in full and 2) give the full citation on the first page. It is permissible to abstract these works so long as credit is given. To copy in all other cases or to republish or to post on a server or to redistribute to lists requires specific permission and payment of a fee. Contact Publisher@InformingScience.org to request redistribution permission.

\section{Introduction}

While the informing science literature embraces both cognitive and psychological elements of informing, future research is called to examine the psychological, sociological, and physiological contexts in which people receive and process information (Cohen, 2009). One such context this paper offers to 
this call is the system user experience, which describes the experience that a person undergoes psychologically when he or she interacts with an information system (IS). Traditionally, IS developers follow the positivistic paradigm ascribing to beliefs that the functionalities of the ISs are of the utmost importance and that functionality is sufficient to ensure that users invariably will use the system to be informed (Tractinsky, 2004). This "build-it-and-they-will-come" approach, however, fails to adequately consider the fact that users are individualistic. As Cohen (2009) observes, a person's neurological, chemical, and hormonal characteristics all contribute to behavior and decision-making in the informing process. Therefore, although employing the right IS development tools are necessary for system success, those tools alone are not sufficient. System developers also must leverage their tools with the right knowledge of users' preferences and intuitions, if they aspire to minimize the amount of bias and misinformation in the informing process.

This study examines how, by exercising a transdisciplinary approach and mindfully working on system interface elements that belong in the aesthetic domain of visual design, system developers may use visual design variables to ripple intended changes into the positivistic domain of system development and on into traditionally IS-related dimensions. Such an approach benefits the informing context because it lessens the randomness in client reaction, a factor that may impede effective informing (Cohen 2009). Because visual impressions are an integral part of the user experience, developers and their systems in the IS discipline benefit from knowledge about managing those visual impressions. This knowledge is inculcated in the aesthetic visual design discipline (Peak, Gibson, \& Prybutok, 2011). For example, beauty is a perception that represents a characteristic of a person, animal, place, object, or idea that provides a perceptual experience of pleasure or satisfaction (Hassenzahl, 2004).

Visual interfaces guide both the visual impressions and the decisions of computer users and exert a powerful influence on their economic, physical, and mental well-being (Hartmann, Sutcliffe, \& De Angeli, 2008). For example, Cyr, Head, and Ivanov (2006) found that an aesthetic mobile device interface contributes to enjoyable and pleasant feelings, which have an impact on user loyalty. Y. Lee and Chen (2011) showed that an aesthetically designed virtual world evokes visitors' affective appraisals of pleasure and enjoyment that enhances their revisit intentions. Cyr, Head, and Larios (2010) found that color appeal on website interface directly contributes to user satisfaction. Wang, Minor, and Wei (2011) reported that e-commerce websites with higher level of aesthetic appeal generate higher level of arousal among customers. Therefore, visual interfaces have the potential of influencing what Cohen (2009) posits is the subject of client-focused research - cognitive and physiological elements of informing.

System designers need an understanding of user preferences to reduce biases in the informing process (Cohen, 2000). This research emphasizes that given the substantial impact visual interfaces have on users, it is imperative that system designers pay particular attention to interface design. Moreover, the process of creating a successful visual system (such as website) is transdisciplinary. For an IS to achieve its goal with minimal bias, this study advocates that designers ensure that visual elements in interface design work together to elicit the desired psychological reactions from users. Thus, the interface blends characteristics of visual design and IS development by applying knowledge of both disciplines (Denning \& Freeman, 2009, Krug, 2006; Lawrence \& Soyhela, 2007; Mullet \& Sano, 1995; Norman, 1998). The resulting visual system should engage the user intuitively while targeting the user's perceptions, preferences, and behavioral intentions (Gefen \& Straub, 2003; Kemp, 2010; Krug, 2006).

The importance of integrating design elements and IS characteristics in system development is broached by Peak, Prybutok, Wu, and Xu's (2011) visual system development (VSD) framework. The framework depicts a typology of constructs, dimensions, and variables employed by professional product designers to achieve a successful visual design. VSD identifies and groups together the diverse visual aesthetic characteristics into three hierarchical "dimensions" (Peak, Pry- 
butok, et al., 2011). Basic elements of visual design (D1 in Figure 1) can be manipulated with the guidance of design principles (D2 in Figure 1) to arrive at high-level and composite visual effects (D3 in Figure 1). The framework also proposes a hierarchical typology of successful IS design factors, grouped into three additional IS dimensions (D4, D5 and D6 in Figure 1).

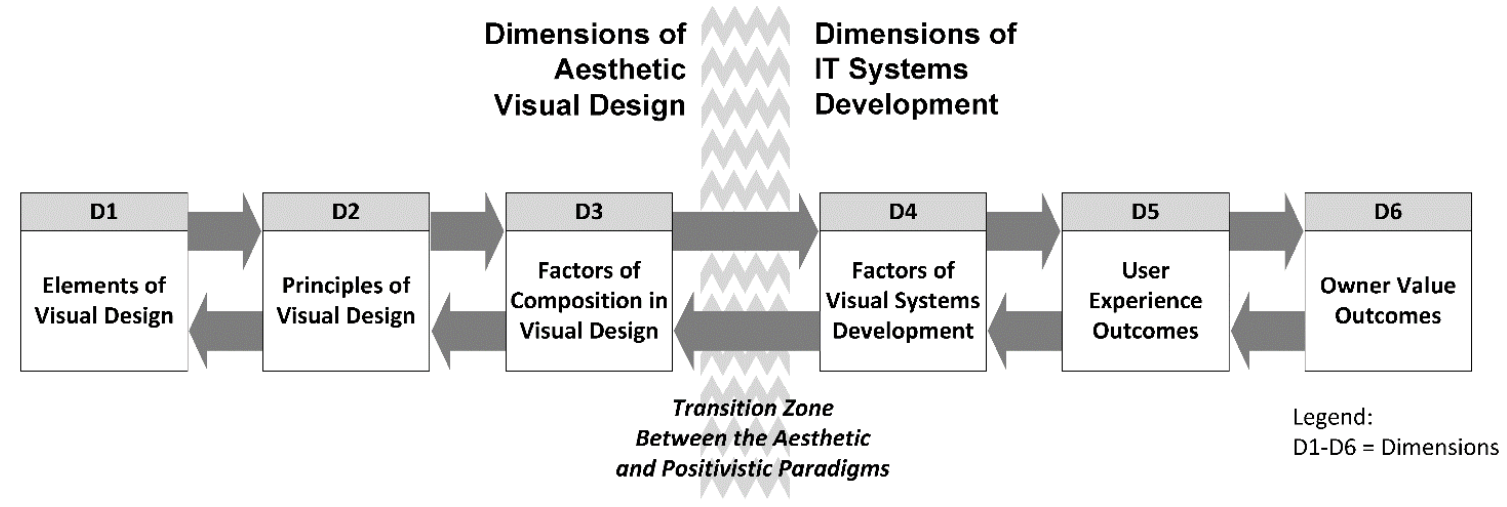

Figure 1. The pluralistic visual systems development model.

Right arrows: Beginning with the aesthetic dimensions, visual designer manipulates the Elements of Design variables (D1); the changes are propagated as concept flows through the model (D2-D6) and across the transition zone (D3-D4) to the computer system (D4), ultimately affecting User Experience (DS) and Owner Value (D6) outcomes.

Left arrows: The owner evaluates the cumulative effects of the changes on System Value and can dictate additional changes to the Elements of Design or other intermediate variables, reversing the direction of the concept flows.

\section{Figure 1. The Pluralistic,Transdisciplinary Visual Systems Development Model}

However, to date, only a limited amount of research has been conducted to test the theoretical relationships of the visual design dimensions with the IS dimensions in VSD (Peak, Gibson, et al., 2011). The purpose of this study is to test whether careful orchestration of visual elements in a system interface is capable of generating the intended perception of the IS on the part of the user. To accomplish this goal, this study designs an experiment based on the VSD framework (Peak, Gibson, et al., 2011; Peak, Prybutok, et al., 2011) with an aim to demonstrate the significant value of aesthetic visual design knowledge as an ingredient necessary to achieve informing success. Taking the first step, the visual experiment focuses on generating and measuring unambiguous perceptions from the user to initially test the model concept, rather than examine subtleties and more complex interactions. Therefore, this paper investigates the following research question: Can system users perceive changes in IS elements that are the result of manipulation of visual design elements in the VSD framework, hence reducing randomness in the informing context?

The experiment is transdisciplinary because it bridges the visual design and IS disciplines, where variable effects introduced on the visual design side of the model ripple to and are perceived in the IS development side of the model. This work both recognizes the complexity of visual aesthetics and examines interrelationships between the factors. This work shows that in the website domain changes in aesthetic elements can be successfully detected by viewers, thus affecting their impressions of interface appearance, a critical factor of IS development success. The present study contributes to the informing science literature because it demonstrates a viable strategy for reducing biases and misinformation in the informing process. The findings in this work suggest that system designers employ the visual characteristics of a system interface from a visual design perspective to achieve better design. 


\section{Literature Review}

\section{Visual Design in IS and Informing Science}

According to Archer (as cited in Frank, 1993, p. 26), "design is that area of human experience, skill and knowledge which is concerned with man's ability to mould his environment to suit his material and spiritual need." More recently, visionary designer Dieter Rams (2010) asserted that design is neither engineering nor science but about making consumer products that focus on ten principles, prominently including innovation, usefulness, aesthetics, understandability, and unobtrusiveness (or transparency).

In this study, "design" is an aesthetic discipline that embraces visual design and interface design. Although it may appear as a remotely related discipline, aesthetic design is in fact advantageous for IS and for informing IS users. Over the last decade, aesthetic visual design for IS products has emerged as a research topic, but a review of these studies reveals two concerns.

First, in the IS discipline, visual aesthetics is not recognized adequately as a complex and multidimensional concept. Aesthetics involves numerous fundamental visual elements; higher-order visual factors derived from applying design guidelines to combine visual elements, and interrelationships among these elements and factors (Peak, Prybutok, et al., 2011). However, prior research has investigated only a limited number of visual elements (or factors) including clarity, color, complexity, focus, and harmony. Second, IS research does not adequately examine the interrelationships among these visual elements: how one choice of color affects another such as the readability of visual design, which subsequently influences users' IS perceptions such as user satisfaction. In summary, research in the technology disciplines that examines visual design with a holistic perspective is scarce.

When visual design is melded with IS as a unit, it is particularly associated with informing science in that it has the potential to address both the sensory and cognitive, task-oriented issues of informers, clients, and channel - three basic components of the informing science framework. In this paper, IS developers or vendors who hire design professionals to develop IS products such as websites are the informers; the interface of an information system, such as a website interface, that disseminates information is the informing channel; the individuals who use the IS such as online shoppers to make decisions are the clients.

According to Cohen (2009), client issues play a pivotal role in the informing process. These are the biological and psychological issues in how clients attend, perceive, and act on information provided; clients may not always behave rationally because all individuals manifest cognitive limitations in making decisions (Cohen 2009). Therefore, examining the effect of visual design becomes an imperative issue for informing science because the desired effect of visual design is to immediately influence perceivers' sensory perceptions, which will initiate a subsequent causal effect on their behaviors. For example, a visually complex web interface in displaying product information decreases online shoppers' satisfaction towards the website, regardless of the quality of the products (Nadkarni \& Gupta, 2007). In contrast, an aesthetically appealing web interface evokes arousal and pleasantness among users; as a result, the users are more likely to "approach" the website (Deng \& Poole, 2010). All these observations suggest how an informing channel is designed, whether or not it is aesthetically pleasing, may predictively influence clients' interpretation of the transmitted information.

For IS, visual design can contribute to the effectiveness of IS, such as websites, as a channel through which information flows from senders to clients. For informing science, visual design addresses "issues involving the media for communicating information" (Cohen, 2009, p.6). Visual elements such as color have been shown to influence information flow in traditional media. 
Gorn, Chattopadhyay, Yi, and Dahl (1997) found that while the visual contents remain constant, a print advertisement designed with different colors exhibits varied impacts on customers' attitudes towards the ad and the product promoted by the ad. According to Agrawala, Li, and Berthouzoz (2011), visual design enhances individuals' abilities to process information because it capitalizes on the human facility for processing visual information and improves information receivers' comprehension, memory, and inference. Visual design assists an audience to quickly identify patterns hidden in large data sets and quickly understand complex ideas. A. Lee (1991) posits that an IS is the environment where IT users should both make critical decisions and make sense of the environment. Thus, visual design is a relevant issue for the stream of informing science research that focuses on informing channels.

In summary, visual design demonstrates great potential as a reference discipline for IS, as suggested by Peak, Prybutok, et al. (2011). Since aesthetics is an important foundation for visual design and some IS studies have approached it, although not from a perspective that fully employs the rich principles and tools of visual design, it is discussed next.

\section{Aesthetics in Studies of IS Use}

Aesthetics is the theory and study of beauty (Hofstadter \& Kuhns, 1976; Runes, 1977; Sheppard, 1987). The aesthetic discipline that deals with the creation of beauty is art, while visual design is an artistic, applied discipline that employs aesthetic theory and visual techniques to achieve a planned product, often for a paying client (Mullet \& Sano, 1995; Rand, 1993). In addition, a sense for what is beautiful is inherent in human nature across all cultures (Sheppard, 1987; Runes, 1977; Hofstadter \& Kuhns, 1976).

In the IS field, cognition-based models play a dominant role in explaining why people use IS. Widely used models include the technology acceptance model (Davis, 1989), the theory of planned behavior (Taylor \& Todd, 1995), the theory of reasoned action (Fishbein \& Ajzen, 1975), the unified theory of acceptance and use of technology (Venkatesh, Morris, Davis, \& Davis, 2003), the innovation diffusion theory (Rogers, 1995), and the social cognitive theory (Compeau \& Higgins, 1995). At the core of cognition-based models are users' beliefs related to the functional characteristics of technologies including perceived usefulness, perceived ease of use, performance and effort expectancy, and relative advantages. Therefore, when it comes to IS development, both researchers and practitioners are attentive to system usability issues (Deng \& Poole, 2010).

Recently, an increasing number of researchers (Beaudry \& Pinsonneault, 2010; Cyr, Head, Larios, \& Bing, 2010; Zhang \& Li, 2004) have realized that IS use involves a set of complex and multifaceted phenomena and that the conventional, cognition-based models fail to capture all of the antecedents of behavior. These works identify the need to investigate the emotional components involved with IT. Some researchers have revealed that both user interface design and website aesthetics facilitate technology adoption by eliciting positive user affect and emotions. For example, Cyr, Head, Larios, and Bing (2010) found that effective visual design of e-commerce websites increases the aesthetic values of the sites and ultimately increases user trust. Hallnäs and Redström (2002) found that the appearance of websites fosters user adoption. van der Heijden (2004) posited that website aesthetics improves work quality. Schenkman and Jönsson (2000) reported that website aesthetics directly influences individual preference of web pages. Moss and Gunn (2009) suggested that the selection of educational websites be based on website aesthetics. Zhao, Lu, Zhang, and Chau (2012) found that visual design of mobile interface, as a significant component of environment quality, influences users' satisfaction with mobile value-added services. Finally, Fynes and Burca (2005) observed that design quality contributes to product quality and customer satisfaction. 
Investigations into IS and aesthetics also have suggested that the aesthetic beauty and effective visual display of system interfaces are realized through using human images (Cyr, Head, Larios, \& Bing, 2010; Hassanein and Head, 2007), manipulating color (Cyr, Head, \& Larios, 2010), and reducing interface complexity (Nadkarni \& Gupta, 2007). While these studies attempt to inculcate aesthetics into the conventional IS development paradigm that centers on system usability and functionalities, it surfaces that aesthetics (or visual elements) also play an important role in guiding web-based IS projects (Vidgen, 2002) and computer game development (Stacey \& Nandhakumar, 2009).

Two observations can be made regarding current IS research that touches on aesthetics. First, in the inquiry of how visual design works, the foci ultimately center on such IS constructs as perceived usefulness, usability, satisfaction, and trust. In IS, little is known about how to design, configure, and optimize a "visual artifact", such as human images and colors, primarily because the majority of studies begin with a single or a combination of finished visual artifact(s). The visual artifact is treated in IT as a black box, with little acknowledgment of its multidimensionality, and is presumed to be a priori complete. For example, color, which is an aesthetic element of visual design has been studied as a design element by IS researchers (Cai, Yu, \& Xu, 2008; Cyr, Head, \& Larios, 2010; De Wulf, Schillewaert, Muylle, \& Rangarajan, 2006; Gruden, 2006; Hassenzahl, 2004; Nadkarni \& Gupta, 2007; Nass, Takayama, \& Brave, 2006; Rose \& Straub, 2001), but primarily as a monolithic variable. Contrastingly, the aesthetic visual design context of color treats it as a complex element, rather than as a variable primitive. To visual designers, color exhibits at least three primary qualities - hue, chroma, luminance - and related and occasionally overlapping secondary qualities such as tint, shade, saturation, complement, associative, analogous, and surface area occupied (Zelanski \& Fisher, 2006). Therefore, while prior IS research shows that color appeal engendered by the choice of one color, say, red, contributes to higher level of e-loyalty, questions still remain unexplored as to how to manipulate the hue, chroma, and luminance of the color to elicit the optimized appealing effects.

Second, IS studies typically treat aesthetics as an over-simplified positivistic construct, for example, containing outcome-oriented characteristics unrecognized by the visual design discipline such as pretty, colorful, and bright (Cyr, Head, \& Larios, 2010) or employing non-visual design descriptors such as simplicity, diversity, colorfulness, and craftsmanship (Moshagen \& Thielsch, $2010,2013)$. In contrast, the visual design discipline enjoys dozens of input-oriented visual characteristics, constructs, variables, and sub-variables, distinct from the outcome-oriented design (Peak, Gibson, et al., 2011). The interrelationships among these true visual-design elements, along with the dissimilar IS-introduced elements, have yet to be disentangled from the scientific perspective.

To summarize, although IS research studies variables classified as characteristics of aesthetic design, such as axis, balance, color, complexity, contrast, layout, legibility, pattern, shape, and space (Awad \& Krishnan, 2006; Nadkarni \& Gupta, 2007; Schenkman \& Jönsson, 2000; Tan \& Lee, 2005; Treiblmaier, 2007), IS does not yet have an accepted framework or methodology that systematically assimilates visual design and its theoretical structure into the systems development process. Moreover, the IS measurement of aesthetic visual variables inadequately accounts for basic conceptual differences between design and IS that include polar views of objectivity, precision, personal value, and emotion. Still, the combined knowledge, theory, and skills of both visual designers and IS professionals is necessary to produce a successful visual system. The functionally oriented IS theory and practice thus can benefit from integrating the mature principles and practices in the design discipline. The VSD framework provides a foundation for such integration (Peak, Prybutok, et al. 2011). 


\section{The VSD Framework}

The VSD framework was the first theoretical effort to integrate elements in visual design and IS disciplines. It was developed by synthesizing the literature from both visual design and IS fields, within the context of an informing environment, and was proposed as a means for visual design to serve as a reference discipline for IS (Peak, Gibson, et al. 2011; Peak, Prybutok, Gibson, \& Xu, 2012). The framework suggests that it is theoretically possible to manipulate visual factors of one discipline (visual design) to increase system success in the other (IS).

The basic premise of VSD is that when designers employ accepted, aesthetic design guidelines to organize basic elementary visual characteristics, such as line, color, visual value, and space, to manipulate the interface of a system, users can sense composite visual characteristics such as complexity and focus from the visual design side of the model. The resulting effects transcend the disciplinary boundary between visual design and IS to influence user perceptions of the system characteristics (the visual design being indistinguishable from the system), which ultimately is conducive to the success of the system. In other words, while a website's visual design is aesthetically-oriented, its implementation is IS-oriented.

VSD contains six ordered dimensions equally distributed between two philosophical paradigms. The aesthetic paradigm underlies the visual design discipline and is composed by Dimensions 1 through 3 (D1, D2, and D3, for short). The positivist paradigm guides IS development and includes Dimensions 4 through 6 (D4, D5, and D6, for short). Between D3 and D4 is a transition zone.

As illustrated by Figure 2, to ensure that the visual interface achieves the intended effects in informing the user, the designer manipulates variables that belong in the Elements of Design dimension (D1). The changes are propagated as concept flows through the other design dimensions (D2, D3). It crosses the transition zone and starts to affect the IS development dimensions, such as User Experience (D5) and Owner Value (D6). Feedback can go from the client back to the designer and is indicated in Figure 2 by the left arrows.

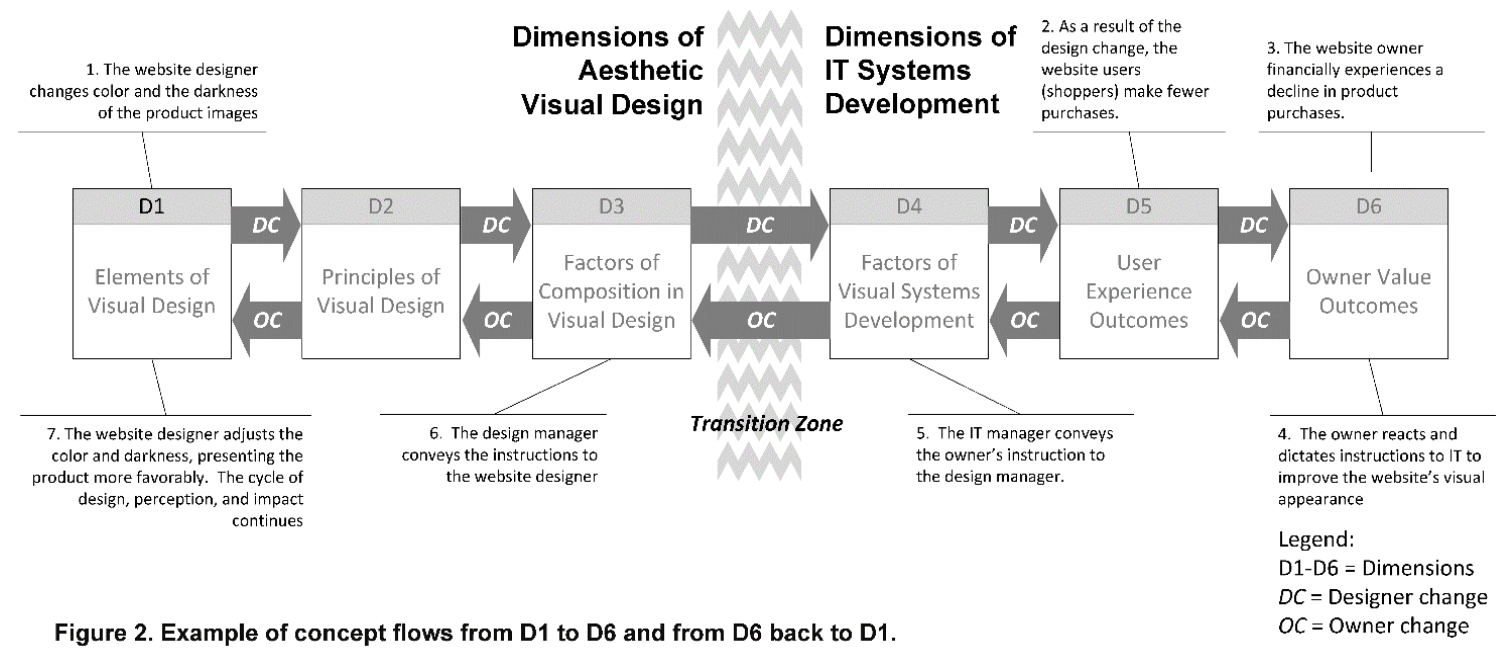

Figure 2. Example of Concept Flows from D1 to D6 and from D6 back to D1

Aesthetic dimension levels in the VSD are fundamental to visual design. The design dimensions (D1 - D3) have existed in theory and practice for some time. The aesthetic design characteristics and their ordered relationships are well known to design research (Peak, Prybutok, et al. 2011). Visual designers view the elements, principles, and compositional factors of visual design as conceptual groupings of characteristics/tools that may be used alone or in combination to form high- 
er-order concepts and effects. The terms variables, dimensions and constructs are unfamiliar in visual design.

Unfortunately, due to paucity of transdisciplinary studies in IS that examine the visual interface of systems, little is known about whether the IS dimensions (D4, D5, D6) can scientifically discern and implement the intentions behind the choice of visual designers. Returning to the example of color, successful use of aesthetic color phenomena in IS dimensions (D4 - D6) may require the skillful use of color in the design dimensions (D1 - D3), with an aesthetic understanding of the nature of color, color theory, color qualities, and the effects of color. When this is done properly, upstream color manipulations hypothetically will cross the transition zone to produce downstream effects in the IS dimension, such as user experience and owner value outcome. Currently, however, this flow of effects has not been tested empirically.

A major contribution of VSD is the identification of a series of visual elements and the arrangement of these elements in a hierarchical order. The notion of VSD responds to previous physiological and anatomical studies, which found that although visual effect is perceived as a whole, the visual system of human beings are subdivided into different areas that perceive different visual components (Livingstone \& Hubel, 1988). Although well argued, a limitation of Peak, Prybutok. et al.'s (2011) work is that it does not provide empirical evidence supporting the use of their VSD framework to design a successful system for the informing users. While the interrelationships within the visual variables and IS variables in the VSD framework are well studied in their own affiliated disciplines, scientific inquiry with regard to the relationship between D3 and D4 that spans across the transition zone is still missing. This empirical study intends to fill the void.

\section{Hypotheses Development}

As mentioned above, pivotal to VSD is that effects of visual interfaces will cross the transition zone between D3 (visual design) and D4 (IS). In this study, signaling theory and the M-R model establish the contention that such transition does occur

Signaling theory originally describes how two parties, such as sellers and buyers, firms and investors, will process limited or hidden information in pre-contractual contexts. Buyers deal with information asymmetry and assess product quality with two types of cues: extrinsic and intrinsic (Richardson, Dick, \& Jain, 1994). Intrinsic cues are product attributes that are fundamentally part of the product. Extrinsic cues are product-related attributes that are not inherent in the product, such as price (Dawar \& Parker, 1994), brand (Erdem \& Swait, 1998), product package and store environment (Baker, Grewal, \& Parasuraman, 1994). For example, the aesthetic appearance of a website (the execution of the visual design) delivers extrinsic cues from which the user infers general website quality, whereas the functionalities (or usefulness) of the website produce intrinsic cues (Wells, Valacich, \& Hess, 2011).

Prior researchers (Zeithaml, 1988) have shown that consumers are more willing to be informed of product quality from extrinsic cues because compared to intrinsic cues, extrinsic cues (1) are more readily available and more easily understood, (2) give consumers more confidence in product assessment, and (3) require less cognitive effort to elaborate on the product of interest.

Consumer reliance on extrinsic cues is particularly true in the Internet context (Wells et al., 2011). Specifically, the aesthetics component of a website emits an extrinsic signal because it functions independently but in parallel with other website attributes. The confidence value of a signal reflects the extent to which customers assess an informational cue with certainty and accuracy. Website aesthetics possesses a high confidence value for two reasons. First, similar to general extrinsic cues (Richardson et al., 1994; Wells et al., 2011), individuals are confident because website aesthetics can be evaluated with less expertise and less prior knowledge of the focal website, and because aesthetics requires less mental effort to absorb. Customers do not need profes- 
sional training to appreciate beauty because that skill is a pre-established genetic attribute that fulfills a basic, biological function (Kogan, 1994, 1997). Second, beyond the website domain, people have long employed aesthetics to generate inferences, for good or bad, due to our probeauty predispositions. According to Cowley (2000, p. 193), "we're designed to care about looks, even though looks aren't earned and reveal nothing about character." A good example is that human beings tend to associate other desirable personal traits to people who are good-looking (Dion, Berscheid, \& Walster, 1972).

Because no one can know everything, people adopt extrinsic signals because they actively look for information processing "shortcuts" or heuristics that help them evaluate better website characteristics (Baker et al., 1994; Wells et al., 2011). In an Internet setting, website users rely on such shortcuts or heuristics more because they cannot interact directly with the entities that run the websites. Thus, when individuals have limited decision-appropriate information about websites, the aesthetics of a website are likely to provide a salient signal for judging website characteristics. Through the interface design, the characteristics are available readily to the user, absorbed instantly, and evaluated easily.

Signaling theory aside, the Mehrabian-Russell (M-R) model provides additional support for the effect of aesthetics on the perceivers' evaluation of IT characteristics (Deng \& Poole 2010). According to the model (Mehrabian \& Russell 1974), emotions mediate the effects of environmental stimuli on human behavior. Different environmental stimuli give rise to different emotions such as arousal and excitement, which subsequently determine the way people respond to those stimuli. The influenced behaviors include individuals' evaluation of IT product characteristics such as IT product quality and other user behaviors regarding the success of IT. Deng and Poole (2010) suggested that aesthetic elements, like visual complexity and order, have the potential to arouse and please website users, thus influencing their impression of the focal websites.

Based on the forgoing arguments, this paper hypothesizes:

In visual systems design (VSD), changes in the aesthetic characteristics can influence system users' perceptions of system characteristics in the informing process.

To test the hypothesis, which rests on the contention that the effects of aesthetic variables are perceived by the broad spectrum of website users, this study constructed a scaled-down model (see Figure 3) that is a subset of VSD, which focuses on factors of website design not usually measured by IS researchers. Of the more than 47 major hierarchical variables and 13 sub-variables that can affect website outcomes (Peak, Gibson, et al., 2011), the present study selects eleven of the major hierarchical variables: two visual, independent variables (color and value), six visual, dependent variables (contrast, balance, emphasis, focus, readability, appearance), and three variables of webpage structure that were held constant (order, complexity, layout).

As shown in Figure 3, the tested model used 12 framework variables composed of 11 of the major hierarchical variables and one outcome variable, user experience. These variables are used to determine if visual systems users at the functional extremes on the IS side of the framework (D5-User Experience Outcomes) are able to detect design changes at the aesthetic extreme (D1-Elements of Visual Design). 


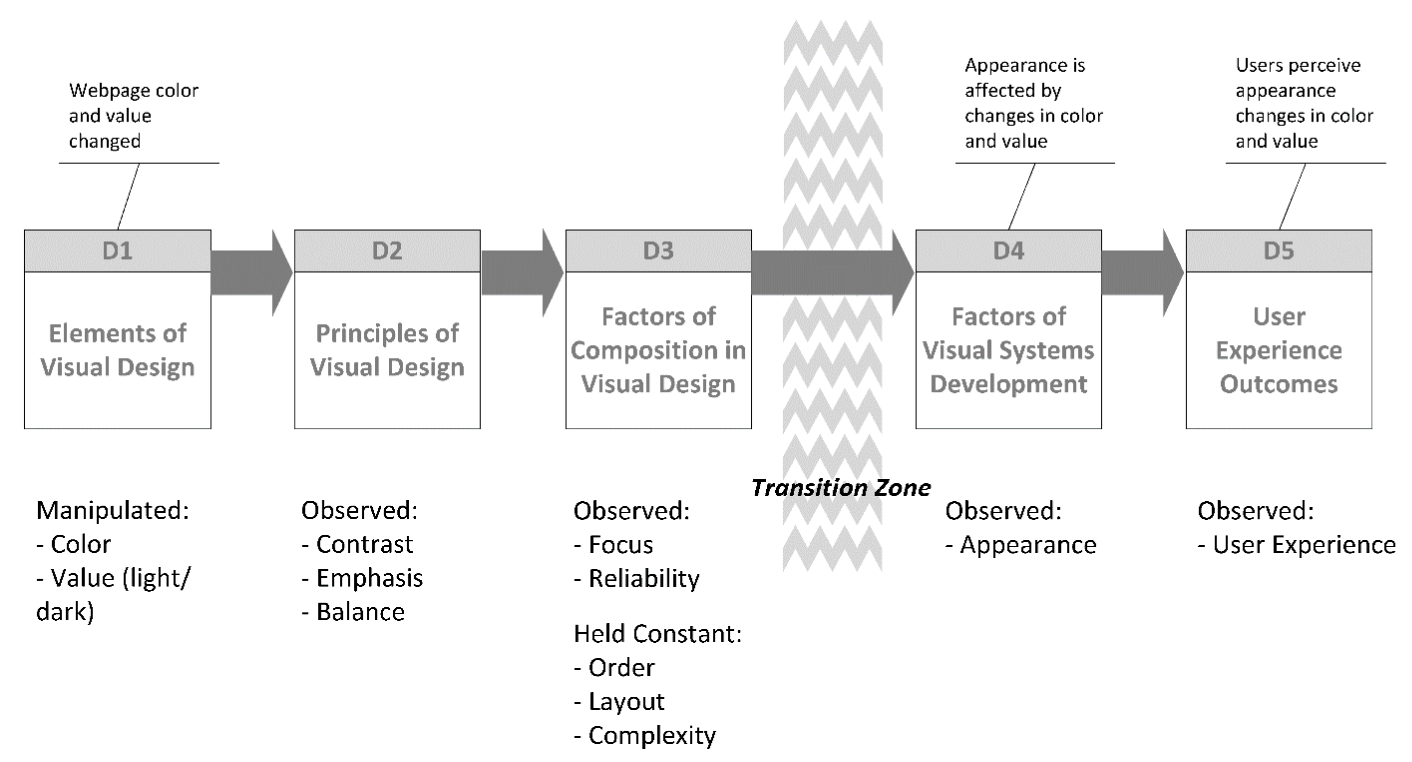

Figure 3. Experimental design.

Beginning with D1, designer manipulates variables Aesthetic Value and Color; changes cause concept flows that affect D2 variables Contrast, Emphasis, and Balance, D3 variables Focus and Readability, and D4 variable Appearance. The user perceives Appearance inD5 User Experience. D3 variables Order, Layout, and Complexity are held constant

Figure 3. Experiential Design

\section{Methodology}

To demonstrate that a conscious choice in design elements can influence the client's perception of the system interface in the informing process, this paper constructed a simple visual experiment (see survey instrument in the Appendix). The downstream website appearance (D4) is a contributing factor of user experience. User Website Experience outcomes (D5) and Website Value outcomes (D6) were not examined because they are beyond the scope of this study.

The researchers measured each variable using a single-item measure to achieve a balance between practical needs and psychometric concerns. The reasons for choosing the single-item measure approach are three-fold. First, the experiment in this study would be time consuming for most of the subjects, requiring that business-oriented subjects learn and use the definitions of six aesthetic variables used to evaluate the six webpages, affording less time for a larger-scale survey. Prior research by Robins et al. (2001) shows that one of the advantages of single-item measures is they are appropriate for studies with time constraints. Second, a single-item measure is advantageous in reducing fatigue, frustration, and boredom during the survey process (Robins, Hendin, \& Trzesniewski, 2001). Because business respondents were required to learn and use previously unfamiliar design terms to answer the survey, they might experience experiment fatigue and be less effective in evaluating the website. In pilot testing, the results showed that some of the respondents experienced a cognitive burden. Therefore, the single-item measure approach is employed to ensure the response quality for this study.

\section{Study Methodology and Instrument Development}

This study aims to demonstrate the general validity of the VSD framework. Figure 3 shows that the instrument used 11 of the major hierarchical variables and one outcome variable, user experience. The researchers manipulated independent variables visual value and color (aesthetic elements of design, at D1) to measure perceived change in the seven dependent variables. The de- 
pendent variables are contrast, emphasis, and balance (aesthetic principles of design, at D2), focus and readability (aesthetic factors of composition, at D3), and appearance (a positivist factor of website development, at D4), which feed the user experience outcome variable. The researchers required that the respondents acquire a basic understanding of only six terms, whose combined effects influence the user experience outcome. The researchers are interested in how changes of visual value and color in D1 influence website appearance in D4 through other aesthetics variables in D2 and D3.

In addition to demographic questions, the instrument contains six groups (one group for each changed webpage) of six identical questions and required an average of less than 10 minutes to complete. The researchers of this paper assured students that their anonymity would be preserved and that participation was voluntary. Students had a choice between completing the questionnaire for extra credit, completing an equivalent extra credit activity, or withdrawing from the study altogether and receiving no credit. In total, 105 of 161 candidate students participated, for a $65.2 \%$ response rate. Appendix includes the entire questionnaire.

For the experiment, the researchers selected a webpage from a commercial website for a small interior design firm in a large metropolitan area. Such a webpage is selected because it demonstrates characteristics of good design (the website itself is for an interior design firm) and because it has an uncomplicated visual organization, a low level of complexity, and a straightforward design layout - characteristics, which were held constant during the experiment. The original version of this webpage was used as the control. Changed versions of the webpage were created using the elements of color and value to test user perceptions of change from the control webpage. This study did not intend to test subtleties of design change. Rather, the purpose is to examine whether subjects from both design (the experts) and business disciplines could perceive different kinds of changes in system characteristics, from the aesthetic paradigm (visual design) across to the positivistic paradigm (IS).

\section{Initial Instrument Development}

The researchers performed three stages of instrument development: alpha, beta, and instrument testing. The alpha testing stage involved a panel of five visual design, information technology, and survey design experts, who developed, tested, and obtained approval for the initial instrument from the University's institutional review board. The beta testing stage involved the review and testing of the instrument by a panel of second-year doctoral students from all five departments in the College of Business. After several more minor revisions, the IRB approved the instrument and deemed it ready for testing, with senior-level design students, all of who were very familiar with the study's aesthetic characteristics. The researchers emailed the instrument to the communication design students who were enrolled in a senior website design course, and next surveyed business students with a diversity of expertise in both an introductory IT course and students in a business presentation course.

In addition to the definition-learning task and the ten demographic questions, the instrument contains six groups of six identical questions and required a range of between 10 and 20 minutes to complete.

The targeted test respondents were undergraduate art visual design students enrolled in a website design course (selected to calibrate the instrument) and undergraduate business students. To account for the disparity in visual design understanding between the two groups, the researchers crafted the study to inquire only about the perceived change between two web pages - a twotailed experimental design. Student respondent groups are appropriate for this study because all of the students used computers in the surveyed courses, and they were familiar with website navigation and the Internet. 
The instrument manipulated in sequence two independent variables: visual value and color (aesthetic elements of design, at D1). The researchers measured perceived change in the six dependent variables and required that the respondents acquire a basic understanding of only six terms, which comprise the dependent variables: contrast, emphasis, and balance (aesthetic principles of design, at D2), focus and readability (aesthetic factors of composition, at D3), and appearance (a positivist factor of IT website development, at D4). The questionnaire contained explanations of these terms, and the Likert-scale radio buttons display popup definitions when the mouse cursor hovers over them (Figure 4). While holding the webpage order, complexity, and layout (D3) constant, the researchers manipulated only the independent variables color and value (D1).

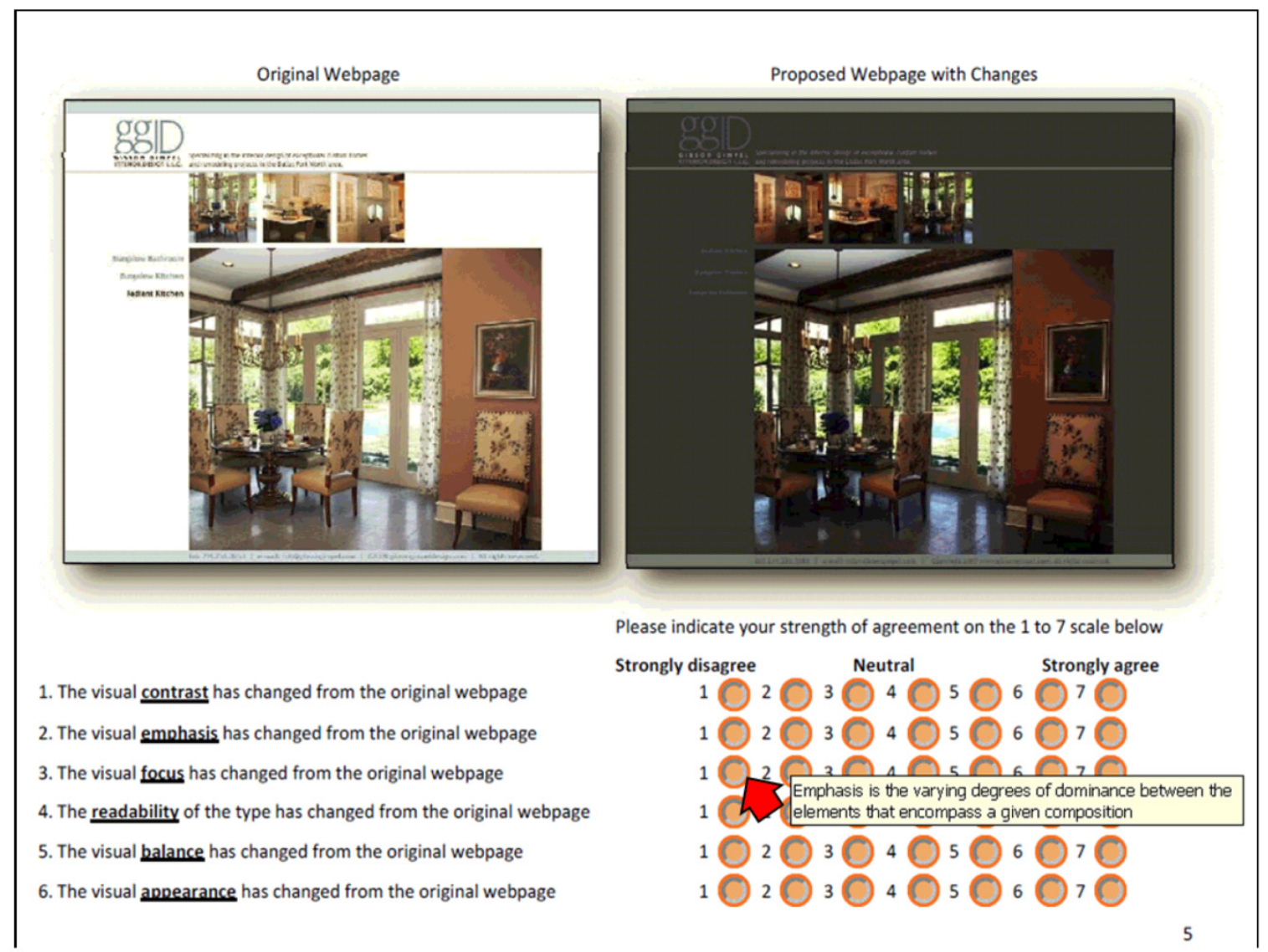

Figure 4. A page from the questionnaire showing an original and a changed webpage, as well as 6 questions asking the degree of perceived change between the two pages. A definition popup appears below the radio button when the respondent cursor hovers above it.

Figure 4. A Page from the Questionnaire Showing an Original and a Changed Webpage

\section{Testing}

For the test, the researchers administered the questionnaire to undergraduate students in four university classes: two senior-level visual design classes in the college of art and visual design, and two junior-level business classes in the college of business.

To ensure that the visual literacy levels in both respondent colleges were adequate to answer the survey, the researchers conducted short training sessions to explain the design terms used in the questionnaire, and then asked the respondents to assess visually the degree of change between a control webpage and a changed webpage (Figure 4). The respondents answered six Likert-scale 
questions on six pages and rated their degree of agreement or disagreement that dependent variables, located at D2, D3, and D4, had changed.

\section{Data and Results}

The researchers collected 105 usable responses from four student respondent groups of normallysighted individuals, "normal" being reported as unimpaired vision by the respondents. 10 are from the initial testing business doctoral group, 18 are from the expert visual design senior group from the art college, 59 are from the first undergraduate business group, and 18 are from the second undergraduate business group. The expert design group's results, whose members all have extensive education and professional training in visual design, show that the group perceives all the changes to the visual appearance of the webpage, despite holding the structure of the webpage constant and despite manipulating only two elementary variables of design: visual value and color. Because the design group had an indepth understanding of how changing the characteristics of the variables affects this particular website's interface while the business groups do not, it is reasonable to believe the design group can serve as a calibrating reference for determining the maximum degree to which untrained webpage users would perceive the effects of manipulating color and value at D1 up through D2, D3, and D4.

Table 1. Descriptive Statistics for Dependent Visual Variables

\begin{tabular}{|c|c|c|c|c|c|c|c|}
\hline \multirow{2}{*}{ Variable } & \multirow{2}{*}{ Paradigm } & & Expert Design & Core Business & Business Design & Business Doctoral & Mean \\
\hline & & & $n=108(18 \times 6)$ & $n=354(59 \times 6)$ & $n=108(18 \times 6)$ & $n=60(10 \times 6)$ & $\begin{array}{l}N=630 \\
(105 \times 6)\end{array}$ \\
\hline \multirow{2}{*}{ Contrast } & \multirow{2}{*}{ Aesthetic } & Mean & 6.5400 & 5.6200 & 6.0600 & 6.2000 & 5.9100 \\
\hline & & S...D. & 1.0970 & 1.6840 & 1.3620 & 1.3500 & 1.5520 \\
\hline \multirow{2}{*}{ Emphasis } & \multirow{2}{*}{ Aesthetic } & Mean & 5.4200 & 5.3600 & 4.7600 & 5.5500 & 5.2800 \\
\hline & & S...D. & 1.8200 & 1.6220 & 1.9900 & 1.4890 & 1.7270 \\
\hline \multirow{2}{*}{ Balance } & \multirow{2}{*}{ Aesthetic } & Mean & 5.0900 & 4.9400 & 4.9800 & 4.0800 & 4.8900 \\
\hline & & S...D. & 2.0530 & 1.8750 & 2.1620 & 2.2270 & 2.0050 \\
\hline \multirow{2}{*}{ Focus } & \multirow{2}{*}{ Aesthetic } & Mean & 5.0200 & 5.2800 & 4.5800 & 5.5500 & 5.1400 \\
\hline & & S..D. & 2.0960 & 1.6170 & 2.1490 & 1.6510 & 1.8270 \\
\hline \multirow{2}{*}{ Readability } & \multirow{2}{*}{ Aesthetic } & Mean & 6.0600 & 5.5700 & 5.6800 & 5.8300 & 5.7000 \\
\hline & & S..D. & 1.5420 & 1.5400 & 1.8280 & 1.6280 & 1.6080 \\
\hline \multirow{2}{*}{ Appearance } & \multirow{2}{*}{ Positivist } & Mean & 6.7900 & 5.8500 & 6.6600 & 6.0300 & 6.1700 \\
\hline & & S...D. & 0.5300 & 1.4790 & 0.7380 & 1.4260 & 1.3130 \\
\hline
\end{tabular}

In the expert design calibration group, approximately 83 percent of the responses for all individuals and all variables are above neutral Likert item 4, establishing a baseline for 83 percent of the items they perceived indicating that visual change had occurred, and for 72 percent of the items they either agreed or strongly agreed that change had occurred. The three business groups with 82 total respondents reflect the same perception patterns with frequencies of 77,78 , and 75 percent above neutral, and 66, 60, and 61 percent in agreement or strong agreement that change had occurred.

Table 1 shows the means for the variables in all groups. Overall, all groups detected the most pronounced changes in visual variables of contrast $($ mean $=5.91)$ and appearance $($ mean $=6.17)$. The variable balance received the lowest score in all groups (mean $=4.89)$, not much larger than the neutral item of 4 .

The means of the respondents from all groups confirmed that all respondents perceived that a visual change had occurred. Generalizing this finding, as research across disciplines has suggested, this study confirms that the effects of aesthetic design can be perceived by most normally sighted individuals, even disciplines as disparate as visual design and IS. The researchers next performed a multivariate analysis of variance (MANOVA) test. The results showed that not all groups were the same with respect to appearance for each of the images. 
To determine how the groups reacted differently in terms of the visual variables, the researchers performed an analysis of variance (ANOVA) test on each of the variables. There are differences in group means for all six variables (see Table 2). Consistent from the above finding about the overall means, the two variables with the most pronounced between-group differences were contrast $[F(3,626)=11.478, p=.000]$ and appearance $[F(3,626)=22.293, p=.000]$.

Table 2. Tests of Between-Group Differences

\begin{tabular}{|l|l|l|l|}
\hline Variable & Paradigm & $\boldsymbol{F}$ & $\boldsymbol{p}$ \\
\hline Contrast & Aesthetic & $11.478^{* * *}$ & 0.000 \\
\hline Emphasis & Aesthetic & $4.282^{* *}$ & 0.005 \\
\hline Balance & Aesthetic & $3.796^{*}$ & 0.010 \\
\hline Focus & Aesthetic & $5.275^{* *}$ & 0.001 \\
\hline Readability & Aesthetic & $2.785^{*}$ & 0.040 \\
\hline Appearance & Positivist & $22.293^{* * *}$ & 0.000 \\
\hline
\end{tabular}

Because the overall $F$ tests for all variables were significant, a series of follow-up tests were performed to evaluate where the differences stemmed from.

Table 3. Planned Contrasts

\begin{tabular}{|c|c|c|c|c|c|c|c|}
\hline \multirow[t]{2}{*}{ Variable } & \multirow[t]{2}{*}{ Paradigm } & \multicolumn{2}{|c|}{$\begin{array}{c}\text { Expert Design } \\
\text { vs. } \\
\text { All Others }\end{array}$} & \multicolumn{2}{|c|}{$\begin{array}{l}\text { Business Design } \\
\text { vs. } \\
\text { All Other Business }\end{array}$} & \multicolumn{2}{|c|}{$\begin{array}{c}\text { Business Doctoral } \\
\text { vs. } \\
\text { Core Business }\end{array}$} \\
\hline & & Value & $p$ & Value & $p$ & Value & $p$ \\
\hline Contrast & Aesthetic & $1.72^{* * *}$ & 0.000 & 0.31 & 0.176 & $.58^{* *}$ & 0.002 \\
\hline Emphasis & Aesthetic & 0.58 & 0.165 & $-1.39 *$ & 0.001 & 0.19 & 0.180 \\
\hline Balance & Aesthetic & $1.28^{*}$ & 0.035 & $.94 *$ & 0.035 & $-.85 * *$ & 0.003 \\
\hline Focus & Aesthetic & -0.35 & 0.301 & $-1.66^{* *}$ & 0.001 & 0.27 & 0.119 \\
\hline Readability & Aesthetic & $1.11^{*}$ & 0.019 & -0.05 & 0.446 & 0.26 & 0.120 \\
\hline Appearance & Positivist & $1.82^{* * *}$ & 0.000 & $1.43^{* * *}$ & 0.000 & 0.19 & 0.178 \\
\hline
\end{tabular}

Because of extensive visual training, the researchers expected members of the expert visual design group to be able to perceive the largest amount of change in the visual variables than the remaining groups. Similarly, thanks to the training the business design group obtained from their coursework, the researchers expected this group to perceive a larger amount of change than did other business groups. The researchers assumed that the business design group would not perceive as large an amount of change as the expert design group because in general the business design group does not have the extensive visual design education and training of the expert design group. Therefore, the researchers performed three planned contrast comparisons: (a) contrast between the expert design group and the other groups; (b) contrast between the business design 
group and the other business groups; and (c) contrast between the remaining two business groups. Table 3 lists the results from these planned contrasts.

In addition, the researchers also carried out post hoc tests to compare all groups pair-wise, for all six variables. Levene's tests were significant, which indicated that the group variance differed for all variables except readability so the researchers used the Games-Howwell procedure for the post hoc tests. Table 4 shows the pair-wise comparison results.

Table 4. Post Hoc Tests

\begin{tabular}{|c|c|c|c|c|c|c|c|c|c|c|c|c|}
\hline \multirow[t]{2}{*}{ Variable } & \multicolumn{2}{|c|}{$\begin{array}{c}\text { Expert Design } \\
\text { vs. } \\
\text { Core Business }\end{array}$} & \multicolumn{2}{|c|}{$\begin{array}{c}\text { Expert Design } \\
\text { vs. } \\
\text { Business Design }\end{array}$} & \multicolumn{2}{|c|}{$\begin{array}{c}\text { Expert Design } \\
\text { vs. } \\
\text { Business Doctoral }\end{array}$} & \multicolumn{2}{|c|}{$\begin{array}{c}\text { Core Business } \\
\text { vs. } \\
\text { Business Design }\end{array}$} & \multicolumn{2}{|c|}{$\begin{array}{c}\text { Core Business } \\
\text { vs. } \\
\text { Business Doctoral }\end{array}$} & \multicolumn{2}{|c|}{$\begin{array}{c}\text { Business Design } \\
\text { vs. } \\
\text { Business Doctoral }\end{array}$} \\
\hline & Value & $p$ & Value & $p$ & Value & $p$ & Value & $p$ & Value & $p$ & Value & $p$ \\
\hline Contrast & $.913^{* * *}$ & 0.000 & $.472^{*}$ & 0.028 & 0.337 & 0.354 & $-.441^{*}$ & 0.030 & $-.576^{*}$ & 0.021 & -0.135 & 0.926 \\
\hline Emphasis & 0.061 & 0.990 & 0.657 & 0.058 & -0.133 & 0.956 & $.597^{*}$ & 0.026 & -0.194 & 0.794 & $-.791^{*}$ & 0.021 \\
\hline Balance & 0.155 & 0.897 & 0.111 & 0.980 & 1.009* & 0.023 & -0.044 & 0.998 & $.855^{*}$ & 0.032 & 0.898 & 0.060 \\
\hline Focus & -0.258 & 0.641 & 0.435 & 0.435 & -0.531 & 0.272 & $.694^{*}$ & 0.012 & -0.273 & 0.636 & $-.967^{* *}$ & 0.008 \\
\hline Readability & $.494^{*}$ & 0.031 & 0.389 & 0.332 & 0.231 & 0.805 & -0.105 & 0.948 & -0.263 & 0.651 & -0.157 & 0.940 \\
\hline Appearance & $.940^{* * * *}$ & 0.000 & 0.13 & 0.450 & $.754 * *$ & 0.001 & $-.810^{* * * *}$ & 0.000 & -0.186 & 0.790 & $.624^{*}$ & 0.012 \\
\hline
\end{tabular}

The findings from the planned contrasts and pair-wise comparisons were mostly consistent with each other and yielded some interesting insights. Findings for the six dependent variables follow:

Contrast: The planned contrasts confirmed our expectation that the expert design group detected a larger amount of change in contrast (group mean was higher by $1.72, p=.000$ ) than did the business groups combined. However, the expectation that the business design group also would detect a larger change than the other business groups did not hold. Interestingly, the business doctoral group detected a larger amount $(.58, p=.002)$ of change than the core business group did.

Correlating the results from planned contrasts with those from the post hoc tests, the researchers found that the higher score for the expert design group was due to the difference (a) between this group and the core business group $(.913, p=.000)$ and $(b)$ between it and the business design group $(.472, p=.028)$, but not between it and the business doctoral group $(.337, p=.354)$. Similarly, the higher business design group mean on the contrast variable was due to the difference between that group and the core business group $(.441, p=.030)$ but not the business doctoral group $(-.135, p=.926)$.

Emphasis: The difference between the expert design group mean on this variable and the other group means was not significant. Oddly enough, the business design group detected a smaller amount of change $(-1.39, p=.001)$ in the emphasis variable than the other business groups. Examining the post hoc test results, the researchers found consistent differences between the business group and the core business group $(-.597, p=.026)$ and the business doctoral group $(-.791, p$ $=.021)$.

Balance: Regarding this variable, the results from planned contrasts and pair-wise comparisons were not consistent. Planned contrasts showed a significant difference (a) between the expert design group and all other groups combined $(1.28, p=.035)$; (b) between the business design group and other business groups $(.94, p=.035)$; and (c) between the business doctoral group and the core business group $(-.85, p=.003)$. The pair-wise post hoc tests, however, did not reveal any related differences. Instead, the business doctoral group was found to detect a smaller amount of change than did the expert design group $(-1.009, p=.023)$ and the core business group $(-.855, p=.032)$. 
Focus: Again, contrary to the researchers' expectation, the business design group detected a smaller amount of change $(-1.66, p=.001)$ in the focus variable than did the other business groups combined. The results from the post hoc tests showed that, indeed, the difference was significant both when compared with the core business group $(-.694, p=.012)$ and the business doctoral group $(-.967, p=.008)$.

Readability: The results from the planned contrasts showed that the expert design group was able to detect a larger amount of change $(1.11, p=.019)$ in this variable than did all other groups combined. However, the pair-wise post-hoc tests revealed that the difference was likely only due to the difference between the expert design group and the core business group $(.494, p=.031)$, but not between it and either the business design group $(.389, p=.332)$ or the business doctoral group $(.231, p=.805)$.

Appearance: Once again, the effect of design training was most conspicuous in relation to this variable, consistent with our observations from the variable means and $F$-values. The results of planned contrasts testified to larger amounts detected by the expert design group $(1.82, p=.000)$ as compared to all other groups combined and by the business design group $(1.43, p=.000)$ as compared to all other business groups. Correlating with the post hoc tests, the researchers found that the expert group indeed detected a larger amount of changes when compared with the core business group $(.940, p=.000)$ and the business doctoral group $(.754, p=.001)$ individually, but not when compared with the business design group $(.130, p=.450)$. The business group, however, was able to detect a larger amount of change even when compared individually with the other two business groups - core business $(.810, p=.000)$ and business doctoral $(.624, p=.012)$.

Summary: In agreement with the general observations of the group means and $F$-tests, the expert design group showed the ability to detect larger amounts of changes in two variables - contrast and appearance. Exposure to design training appears to have played a role in the respondents' ability to detect changes in these variables. In other words, even a little design training appears to benefit the user's ability to perceive qualities of appearance.

By contrast, based on results from the planned contrasts and pair-wise post hoc tests, it was unlikely that training has influenced, in a palpable way, the respondents' ability to detect changes in emphasis, focus, and readability. In other words, the respondents already have established their sensitivity to these variables, so that design training does not appear to increase perception. In addition, our findings in regard to the groups' ability to detect changes in the balance variable were largely inconclusive. Further examination of individuals' ability to detect a change in this variable is needed. Finally, although the business doctoral group did not detect changes in these variables as large as the design groups, in some cases it could detect slightly larger amounts of changes than did the core business group.

\section{Discussion}

The client-focused research in informing science calls for more scrutiny of the client's cognitive, physiological, and psychological elements (Cohen 2009). A psychological element, individuals' aesthetic perception, is worth studying because visual design choices can affect how individuals use their aesthetic feeling toward the system as an extrinsic cue for evaluating the system, hence influencing effectiveness and character of the informing process. The current evolving visual nature of IS prompts us to stress how, across paradigms and disciplines, the aesthetic design informs and influences the client. While Peak, Prybutok, et al.'s (2011) prior work proposes that visual design serves as a reference discipline for IS, their theory lacks empirical evidence. In response to their call for a pluralistic, transdisciplinary solution that integrates shared wisdom of visual design and IS into a shared foundation of knowledge and practice, this work tests the validity of VSD by confirming the relationship between two groups of variables. 
In the survey instrument, this study focuses on factors of website design that are not traditionally measured by IS researchers. To demonstrate that the effects of aesthetic variables are perceived by a broad spectrum of website users, the researchers surveyed visual designers and business individuals from four sample groups. Included in those groups were one group where the respondents possessed formal design expertise and three groups without formal design expertise. The results confirm that the effects of aesthetic visual design are perceived by most normally-sighted individuals regardless of professional background. All respondents perceived changes originating in the upstream design (aesthetic) variables, crossing the transition zone, and manifesting in the downstream IS (positivist) variables.

This study also contains findings with important implications for informing science. First, the experiment empirically demonstrates that the selected sequence of hierarchical and interactive visual design characteristics manipulated by designers (acting within the aesthetic paradigm) are clearly perceived by users of the IS (acting within the positivist paradigm). Thus, this study provides preliminary empirical support for the VSD framework and bolsters an argument within the informing science framework that system designers need a better understanding of the cognitive and physiological elements behind user behaviors (Cohen 2009).

Second, this research provides guidance for improving the quality of information conveyed by the informing process. Cohen (2009) suggests that attention be directed toward the potential bias, misinformation, and disinformation in the informing systems. These negative effects, as this study shows, may be reduced through careful system design. In this study, the scores and means of the respondents for all groups confirmed that all respondents - whether they possessed design expertise or not - perceived that visual changes had occurred, and that all groups perceived similar directions and intensities of those changes. It appears that there are a number of aesthetic perceptions that are fairly stable across people, irrespective of their individual differences. In addition, visual design elements can be manipulated so that when those perceptions are affected, no substantial deviation will occur from the intended results of the designers. Of course, this requires good understanding of principles in aesthetics and visual design and skillful and disciplined use of design tools. Therefore, although differences abound between individuals and absolute uniformity can never be achieved, it still is feasible to create generally similar informing outcomes in individuals if design elements are used mindfully, with good planning and design.

Third, this research introduces guidance for the design of transdisciplinary informing channels. Another area of future informing science research suggested by Cohen (2009) is channel-focused research. Research is needed to discover how informing networks are impacted by the informing context and how client characteristics may influence the informing process and its evolution. Our study uncovers a client characteristic, their aesthetic perception, which may influence the design of informing channels. To date, system designers typically embrace the positivistic paradigm of IS and have not adequately considered aesthetic design variables, their impact on system aesthetics, and in turn, the ultimate consequences for users - how they view the system interface aesthetically and whether the aesthetic evaluation facilitates or impedes the informing process. As this study shows, some aesthetic design variables that are well-known to visual designers can be perceived unambiguously by both designers and business individuals. When designing an informing channel, such variables should be given adequate attention.

Finally, this research is a vehicle for IS by confirming the importance of visual design to IS development and describing a visual, transdisciplinary channel for informing both theorists and users of the IS discipline. Gill and Bhattacherjee (2009) argue that the IS discipline is facing serious challenges in the area of informing because IS researchers do not adequately consider important clients such as practitioners. Integrating IS development with the visual design discipline offers a means to deal with the challenge because the latter has enjoyed a mature practitioner con- 
stituency. By seriously deploying design techniques in system development, the IS discipline can appeal to that practitioner constituency and gather its support in the informing process.

\section{Limitations and Future Research}

One limitation of the present paper is that, for parsimoniousness, it did not examine the impact of website appearance, a factor of visual systems development (D4) on the user experience outcomes (D5) or the website owner outcomes (D6). These are topics for future research. Both D4 and D5 fall into the domain of IS, and previous Human-Computer Interface (HCI) work in Management Information Systems (MIS) has demonstrated that D4 affects D5. The gap, however, is that little has been done to connect the visual field to the IS field, for example, how visual factors such as D1, D2 and D3 affect the IS variables is unknown. The main purpose of this study is to examine the crossing of the transition zone between D3 and D4. Future research may investigate the impacts of different visual elements in the aesthetic paradigm on D4 or subsequent dimensions of D5 and D6 in VSD that are more directly related to IS success.

A second limitation is that the experimental design does not involve randomization. Rather, this study designed a free simulation experiment (Fromkin \& Streufert, 1976). The choice of this experimental method is consistent with previous research in similar topics (Gefen \& Straub, 2000, 2003). Despite the advantages that it creates real-world scenarios, solicits subjects' responses to experimental tasks as naturally as possible, and maximally eliminates any confounding effects (Gefen \& Straub, 2003), future research could examine the topic with the randomized experimental design approach to further validate the findings of the paper.

Notwithstanding the forgoing limitations, this experiment provides empirical evidence of the connection between the visual world and the IS world. Such a connection represents the first empirical step to test Peak, Prybutok et al.'s (2011) pluralistic transdisciplinary framework of visual design. Moreover, this work provides a foundation for future research to address the development of computer interface design, including website design. Such future research is likely to cross both philosophical and disciplinary boundaries. Better-integrated interfaces provide a better user experience, communicate better, and yield better results from the informing process.

Future research may test the relationships of other VSD variables within the informing environment; particularly how changes on visual variables may influence IS users' perceptions with regard to system success factors. In addition, recent IS research has witnessed the rise of user emotions in predicting system usage. Future studies may examine how visual aesthetic informs and subsequently impacts the IT user emotions such as relaxation, pleasure, and excitement. Study of emotion is consistent with the client-focused research that there is a need to further the study of informing science (Cohen 2009).

\section{Conclusion}

Prior informing science research has shown that users play an important role in informing systems (Gill \& Bhattacherjee, 2007). As Cohen (2009) asserted, it is imperative to investigate how individuals psychologically attend, perceive, and act on the information provided. The transdisciplinary nature of visual design affects how systems function within the informing environment (Peak, Prybutok, et al. 2011). However, little prior research has demonstrated how such an effect occurs. The study provides important insights that help address this gap within the informing environment.

This current study illustrates a specific proposition that while the structural organization of a webpage that includes order, complexity, and layout can remain unchanged, changes on visual elements such as visual value and color can eventually affect viewers' perceptions of website appearance, which directly feeds the user experience outcome variables and influences IS use and 
success. Through its examination of the interrelationships between the visual design factors, this study demonstrates that upstream changes in the aesthetic design factors (visual value and color) can influence downstream user perceptions of IS characteristics (appearance). Furthermore, even a little design training appears to benefit the perception of appearance, suggesting that accumulated experience of quality visual design increases the visual sophistication (and expectations) of users.

These observations demonstrate the significant value of aesthetic visual design knowledge as an ingredient necessary to success of the informing process, and indicate the need for IS developers to acquire visual design knowledge. When IS developers perform website design, they are using, directly or indirectly, aesthetic characteristics, because the system user inevitably will perform a visual assessment of the developers' work and aesthetics is a central part of visual effects.

\section{References}

Agrawala, M., Li, W., \& Berthouzoz, F. (2011). Design principles for visual communication. Communications of the ACM, 54(4), 60-69.

Awad, N., \& Krishnan, M. (2006). The personalization privacy paradox: An empirical evaluation of information transparency and the willingness to be profiled online for personalization. MIS Quarterly, 30, $13-28$.

Baker, J., Grewal, D., \& Parasuraman, A. (1994). The influence of store environment on quality inferences and store image. Journal of Academy of Marketing Science, 22(4), 328-339.

Beaudry, A., \& Pinsonneault, A. (2010). The other side of acceptance: Studying the direct and indirect effects of emotions on information technology use. MIS Quarterly, 34, 689-710.

Cai, S., Yu, J., \& Xu, Y. (2008). The effects of web site aesthetics and shopping task on consumer online purchasing behavior. CHI 2008 Proceedings (pp. 3477-3483), Florence, Italy.

Cohen, E. B. (2000). Failure to inform: Errors in informing systems. Proceedings of the 2000 Americas Conference on Information Systems, August 10-13 ${ }^{\text {th }}, 2000$, Long Beach, California, p1057-1061.

Cohen, E. B. (2009). A philosophy of informing science. Informing Science: the International Journal of an Emerging Transdiscipline, 12, 1-15. Retrieved December 9th 2013, from http://www.inform.nu/Articles/Vol12/ISJv12p001-015Cohen399.pdf

Compeau, D. R., \& Higgins, C. A. (1995). Application of social cognitive theory to training for computer skills. Information Systems Research, 6, 118-143.

Cowley, G. (2000). The biology of beauty. In W. Lesko (Ed.), Readings in social psychology: General, classic, and contemporary selections (4th ed., pp. 188-194). Boston, MA: Allyn \& Bacon.

Cyr, D., Head, M., \& Ivanov, I. (2006). Design aesthetics leading to m-loyalty in mobile commerce. Information \& Management, 43, 950-963.

Cyr, D., Head, M., \& Larios, H. (2010). Colour appeal in website design within and across cultures: A multi-method evaluation. International Journal of Human-Computer Studies, 68, 1-21.

Cyr, D., Head, M., Larios, H., \& Bing, P. (2010). Exploring human images in website design: A multimethod approach. MIS Quarterly, 33, 539-566.

Davis, F. D. (1989). Perceived usefulness, perceived ease of use, and user acceptance of information technology. MIS Quarterly, 13, 319-339.

Dawar, N., \& Parker, P. (1994). Marketing universals: Consumers' use of brand name, price, physical appearance, and retail reputation as signals of product quality. Journal of Marketing, 58, 81-95.

De Wulf, K., Schillewaert, N., Muylle, S., \& Rangarajan, D. (2006). The role of pleasure in web site success. Information \& Management, 43, 434-446. 
Deng, L., \& Poole, M. S. (2010). Webpage visual design, webpage visual complexity, webpage order, emotional response, approach behavior. MIS Quarterly, 34(4), 711-730.

Denning, P., \& Freeman, P. (2009). The profession of it computing's paradigm. Communications of the $A C M, 52,28-30$.

Dion, K., Berscheid, E., \& Walster, E. (1972). What is beautiful is good. Journal of Personality and Social Psychology, 24(3), 286-290.

Erdem, T., \& Swait, J. (1998). Brand equity as a signaling phenomenon. Journal of Consumer Psychology, $7(2), 131-157$.

Fishbein, M., \& Ajzen, I. (1975). Belief, attitude, intention, and behavior: An introduction to theory and research. Reading, MA: Addison-Wesley.

Frank, B. (1993). Teaching technology. London, UK: Routledge.

Fromkin, H. L., \& Streufert, S. (1976). Laboratory experimentation. In B. Dunnette (Ed.), Handbook of industrial and organizational psychology (pp. 415-465). Chicago: Rand McNally College Publishing Company.

Fynes, B., \& Búrca, S. D. (2005). The effects of design quality on quality performance. International Journal of Production Economics, 96, 1-14.

Gefen, D., \& Straub, D. (2000). The relative importance of perceived ease of use in IS adoption: A study of ecommerce adoption. Journal of the Association for Information Systems, 1(8), 1-30.

Gefen, D., \& Straub, D. (2003). Managing user trust in B2C e-services. e-Service Journal, 2, 7-24.

Gill, T. G., \& Bhattacherjee, A. (2007). The informing sciences at a crossroads: The role of the client. Informing Science: the International Journal of an Emerging Transdiscipline, 10, 17-39. Retrieved December 9th 2013, from http://www.inform.nu/Articles/Vol10/ISJv10p017-039Gill317.pdf

Gorn, G. J., Chattopadhyay, A., Yi, T., \& Dahl, D. W. (1997). Effects of color as an executional cue in advertising: They're in the shade. Management Science, 43(10), 1387-1400.

Gruden, J. (2006). Human factors, CHI, and MIS. In P. Zhang \& D. Galletta (Eds.), Human-computer interaction and management information systems (pp. 302-421). Ardmonk, New York: M.E. Sharpe.

Hallnäs, L. \& Redström, J. (2002). From use to presence; on the expressions and aesthetics of everyday computational things. ACM Transactions on Computer-Human Interaction, 9(2), 106-124.

Hartmann, J., Sutcliffe, A., \& De Angeli, A. (2008). Towards a theory of user judgment of aesthetics and user interface quality. ACM Transactions on Computer-Human Interaction, 15, 15-30.

Hassanein, K., \& Head, M. (2007). Manipulating perceived social presence through the web interface and its impact on attitude towards online shopping. International Journal of Human-Computer Studies, 65, 689-708.

Hassenzahl, M. (2004). The interplay of beauty, goodness, and usability in interactive products. HumanComputer Interaction, 19, 319-349.

Hofstadter, A., \& Kuhns, R. (1976). Philosophies of art and beauty: Selected readings in aesthetics from Plato to Heidegger. Chicago, Illinois: University of Chicago Press.

Kemp, K. (2010). Less and more: The design ethos of Dieter Rams. Berlin, Germany: Gestalten.

Kogan, N. (1994). On aesthetics and its origins: Some psychobiological and evolutionary considerations. Social Research, 61, 139-165.

Kogan, N. (1997). Reflection on aesthetics and evolution. Critical Review, 11, 193-210.

Krug, S. (2006). Don't make me think: A common sense approach to web usability. Berkeley, California: New Riders Publishers. 
Lawrence, D. \& Soyhela, T. (2007). Balanced website design: Optimizing aesthetics, usability, and purpose. London, UK: Springer Verlag.

Lee, A. S. (1991). Architecture as a REFERENCE DISCIPLINE for MIS. In H. E. Nissen, H. K. Klein \& R. Hirschheim (Ed.), Information systems research: Contemporary approaches \& emergent traditions (pp. 573-592). Amsterdam: North Holland.

Lee, Y. \& Chen, A. (2011). Usability design and psychological ownership of a virtual world. Journal of Management Information Systems, 28(3), 269-308.

Livingstone, M. \& Hubel, D. (1988). Segregation of form, color, movement, and depth: Anatomy, physiology, and perception. Science, 240(4853), 740-749.

Mehrabian, A., \& Russell, J. A. (1974). An approach to environmental psychology. Cambridge, MA: MIS Press.

Moshagen, M., \& Thielsch, M. T. (2010). Facets of visual aesthetics. International Journal of HumanComputer Studies, 68, 689-709.

Moshagen, M., \& Thielsch, M. T. (2013). A short version of the visual aesthetics of websites inventory. Behaviour \& Information Technology, 32(12), 1305-1311.

Moss, G. A., \& Gunn, R.W. (2009). Gender differences in website production and preference aesthetics: Preliminary implications for ICT in education and beyond. Behaviour \& Information Technology, 28(5), 447-460.

Mullet, K., \& Sano, D. (1995). Designing visual interfaces: Communication oriented techniques. Upper Saddle River, New Jersey: Pearson, Prentice Hall.

Nadkarni, S., \& Gupta, R. (2007). A task-based model of perceived website complexity. MIS Quarterly, 31, 501-524.

Nass, C., Takayama, L., \& Brave, S. (2006). Socializing consistency: From technical homogeneity to human epitome. In P. Zhang \& D. Galletta (Eds.), Human-computer interaction and management information systems (pp. 373-391). Ardmonk, New York: M.E. Sharpe.

Norman, D. (1998). Invisible computer: Why good products can fail, the personal computer is so complex and information appliances are the solution. Cambridge, MA: MIT Press.

Peak, D., Gibson, M., \& Prybutok, V. (2011). Synergizing positivism and aesthetics in the design process of interactive visual systems. Information Design Journal, 19, 103-121.

Peak, D., Prybutok, V., Wu, Y., \& Xu, C. (2011). Integrating the visual design discipline with information systems research and practice. Informing Science: The International Journal of an Emerging Transdiscipline, 14, 161-181. Retrieved from http://www.inform.nu/Articles/Vol14/ISJv14p161181Peak603.pdf

Peak, D., Prybutok, V., Gibson, M., \& Xu, C. (2012). Information systems as a reference discipline for visual design. International Journal of Art, Culture and Design Technologies, 2(2), 57-71.

Rams, D. (2010). Ten principles for good design. London, UK: Vitsoe.

Rand, P. (1993). Design, form, and chaos. New Haven, Connecticut: Yale University Press.

Richardson, P. S., Dick, A. S., \& Jain, A. K. (1994). Extrinsic and intrinsic cue effects on perceptions of store brand quality. Journal of Marketing, 58(4), 28-36.

Robins, R. W., Hendin, H. M., \& Trzesniewski, K. H. (2001). Measuring global self-esteem: Construct validation of a single-Item measure and the Rosenberg self-esteem scale. Personality and Social Psychology Bulletin, 27(2), 151-161.

Rogers, E. (1995). Diffusion of innovation. New York: Free Press.

Rose, G., \& Straub D. (2010). The effect of download time on consumer attitude toward the e-service retailer. e-Service Journal, 1, 55-76. 
Runes, D. (1977). Dictionary of philosophy. Totowa: Littlefield, Adams \& Co.

Schenkman, B., \& Jönsson, F. (2000). Aesthetics and preferences of web pages. Behaviour \& Information Technology, 19, 367-377.

Sheppard, A. (1987). Aesthetics: An introduction to the philosophy of art. Oxford and New York: Oxford University Press.

Stacey, P., \& Nandhakumar, J. (2009). A temporal perspective of the computer game development process. Information Systems Journal, 19, 479-497.

Tan, G., \& Lee, E. (2005). Using protocol analysis to understand the effects of web site design on consumer purchase behaviors. Proceedings of International Conference of Information Systems (pp. 937950), Las Vegas, Nevada, USA.

Taylor, S., \& Todd, P. A. (1995). Understanding information technology usage: A test of competing models. Information Systems Research, 6, 144-176.

Tractinsky, N. (2004). Toward the study of aesthetics in information technology. Proceedings of the 25th International Conference on Information Systems (pp. 771-780), Washington, DC, USA.

Treiblmaier, H. (2007). Website analysis: A review and assessment of previous research. Communication of the Association for Information Systems, 19, 806-843.

van der Heijden, H. (2004). User acceptance of hedonic information systems. MIS Quarterly, 28(4), 695704.

Venkatesh, V., Morris, M. G., Davis, G. B., \& Davis, F. D. (2003). User acceptance of information technology: Toward a unified view. MIS Quarterly, 27, 425-478.

Vidgen, R. (2002). Constructing a web information system development methodology. Information Systems Journal, 12, 247-261.

Wang, Y., Minor, M., \& Wei, J. (2011). Aesthetics and the online shopping environment: Understanding consumer responses. Journal of Retailing, 87(1), 46-58.

Wells, J. D., Valacich, J. S., \& Hess, T. J. (2011). What signals are you sending? How website quality influences perceptions of product quality and purchase intentions. MIS Quarterly, 35(2), 373-396.

Zeithaml, V. (1988). Consumer perceptions of price, quality and value: A means-end model and synthesis of evidence. Journal of Marketing, 52(3), 2-22.

Zelanski, P., \& Fisher, M.P. (2006). Color. Upper Saddle River, New Jersey: Pearson, Prentice Hall.

Zhang, P., \& Li, N. (2004). Love at first sight or sustained effect? The role of perceived affective quality on users' cognitive reactions to information technology. Proceedings of International Conference on Information Systems (pp. 283-296). Washington, D.C., USA.

Zhao, L., Lu, Y., Zhang, L., \& Chau, Y. K. (2012). Assessing the effects of service quality and justice on customer satisfaction and the continuance intention of mobile value-added services: An empirical test of a multidimensional model. Decision Support Systems, 52, 645-656. 
Peak, Prybutok, Gibson, Wu, \& Xu

\section{Appendix: Website Questionnaire}

I. Introduction to the Survey

Informed Consent Notice

The purpose of this research study is to test a website user's ability to detect visual changes in web pages. Because most students are sophisticated users of websites and website technologies, it is important to obtain your feedback about a web user's sensitivity to visual changes in webpage design.

You are being asked to complete a survey that will take about 20 minutes of your time. By completing the survey you are giving consent to participate and confirming that you are at least 18 years old. Results of the survey will be reported only on a group basis. Answering the questions in this survey involves no foreseeable risks. Participation is voluntary and you may stop at any time without penalty.

Your decision to participate or to withdraw from the study will have no effect on your course grade. If you do not want to participate you can still obtain the same extra credit that is being offered for participation in this survey by asking your instructor for the alternate assignment option.

If you have any questions regarding this study, please contact either member of the College of Business / College of Visual Arts and Design research team - Dr. Daniel Peak at 940-369-7210 (peak@unt.edu) ), Prof. Michael Gibson at 940-369-7233 (gibson@unt.edu), or Dr. Victor Prybutok at 940-565-4767 (Prybutok@unt.edu).

This research project has been reviewed and approved by the UNT Institutional Review Board (940) 565-3940. Contact the UNT IRB with any questions regarding your rights as a research subject.

You may print this notice for your records.

This survey requires Acrobat Reader 7.0 or higher. If you experience problems answering the survey, please download and install the latest Adobe Acrobat Reader from http://get.adobe.com/reader/?promoid=BUIGO

If you proceed and complete this survey you are providing consent to participate in this study.

Rev. 3.4b. 
II.

Demographic Information

For instructions, please hold the cursor above a radio button for two seconds

1. What is your gender?

$$
\text { Male Female }
$$

2. What is your classification at UNT?

$$
\text { Fresh Soph }(1 \text { Junior }(\text { Senior }(9) \text { Grad }(
$$

3. What is your major field?

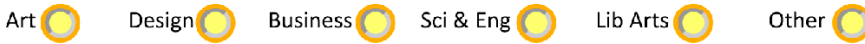

4. What is your age?

$$
18-20 \bigcirc \quad 21-25 \bigcirc \quad 31-40 \bigcirc 41 \text { or over }(26
$$

5. Do you have visual difficulty distinguishing colors?

$$
\text { No Slight } O \text { Yes } 0
$$

6. What is your level of artistic training?

None Pre HSO HSO College (

7. What is your level of work experience?

$$
\text { None Part-time FT 1-3yrs FT 4-6yrs FT }>6 \text { yrs }(
$$

8. What is your level of visual web use experience?

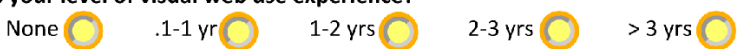

9. What is your level of technical web development experience?

$$
\text { None } \quad .1-1 \text { yr } 1-2 \text { yrs } 2-3 \text { yrs } \bigcirc>3 y r s(
$$

10. What is your level of visual web design experience?

$$
\text { None } 1-1 \mathrm{yr} \quad 1-2 \mathrm{yrs} \quad 2-3 \mathrm{yrs}(3 \mathrm{yrs}
$$


Peak, Prybutok, Gibson, Wu, \& Xu

\section{Website Information}

\section{Introduction}

The following professionally-designed company webpage is the entry portal for an interior design firm. The primary purpose of this webpage is to display to prospective clients rooms the designers have created for existing clients. Prospective clients will be directed initially to this page, but may decide-in a few seconds - whether to leave or to stay a little longer at the website.

The researchers are experimenting with changes to the webpage. As you view the changed webpage ("proposed webpage with changes"), this survey asks you if you agree or disagree that change has occurred. If you see absolutely no change in the webpage, then please select the strongly disagree radio button. If you see a great deal of change in the webpage, please select the strongly agree radio button.

The researchers are only asking you to answer whether or not change has occurred. They are not asking you to determine whether that change was good or bad. Based on your understanding of the importance of the visual webpage design and your knowledge of the design characteristics, please indicate your agreement or disagreement of the degree of the change (if any) from the original webpage.

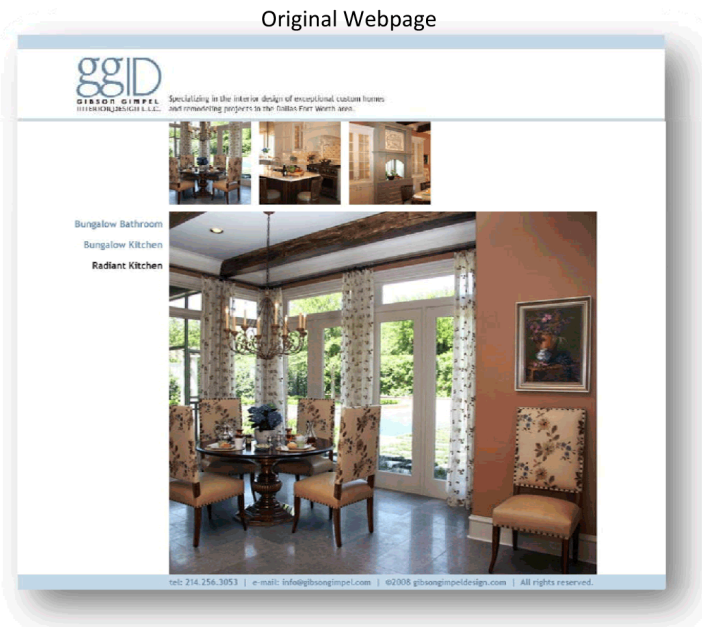




\section{User Perceptions of Aesthetic Visual Design Variables}

The following terms are used in this survey. They will be explained before you are asked to complete the survey. You will be given a glossary of these terms to answer the survey.

Appearance A visual perception factor of Website development. Appearance is a general measure of visual perception, the outward, first impression of the website or webpage on the user.

Balance The symmetrical or asymmetrical arrangement of objects as it relates to their visual weight within a composition; the characteristic of visual weight or stability. The visual reconciliation of opposing forces, usually achieved with the qualities of symmetry or asymmetry.

Color Color is the perception of particular wavelengths of light as specific hues by the color receptors of the human eye, called cones; it is the visual perception of red, green, and blue light waves. I he three types of cones are sensitive to variations in light waves of varying lengths; stimulation of the cone receptors by variations of visible light is interpreted as color.

Contrast Contrast is the visual dissimilarity of adjacent or juxtaposed design elements in an image. Contrast is frequently used to create interest or excitement in a visual work.

Emphasis Emphasis relates to the creation of varying degrees of dominance between the elements that comprise a given composition. One or more points of focus or interruption; it marks the locations in a composition which most strongly draw the viewers' attention.

Focus Focus is a particular area of attention or detail in a composition. It is the central or critical point of interruption. Whereas the principle of Emphasis may embrace multiple, hierarchical points of interest, the focus of the composition is the location where the eye always returns.

Readability Readability is a measure of the ease that a viewer can read the text passages on a website. Readability includes the typography, layout, and placement of the text.

Value

Value is the relative lightness (tint) or darkness (shade) of a hue. According to Edwards (2003, p. 79), "value is the attribute measuring how colors compare on the gray scale in which: white reflects $100 \%$ and absorbs $0 \%$, middle gray reflects $50 \%$ and absorbs $50 \%$, and black reflects $0 \%$ and absorbs $100 \%$. Tinting a color (with white) gives it a lighter value. Shading a color (with black) gives it a darker value." The qualities of value include contrast and gradation." 

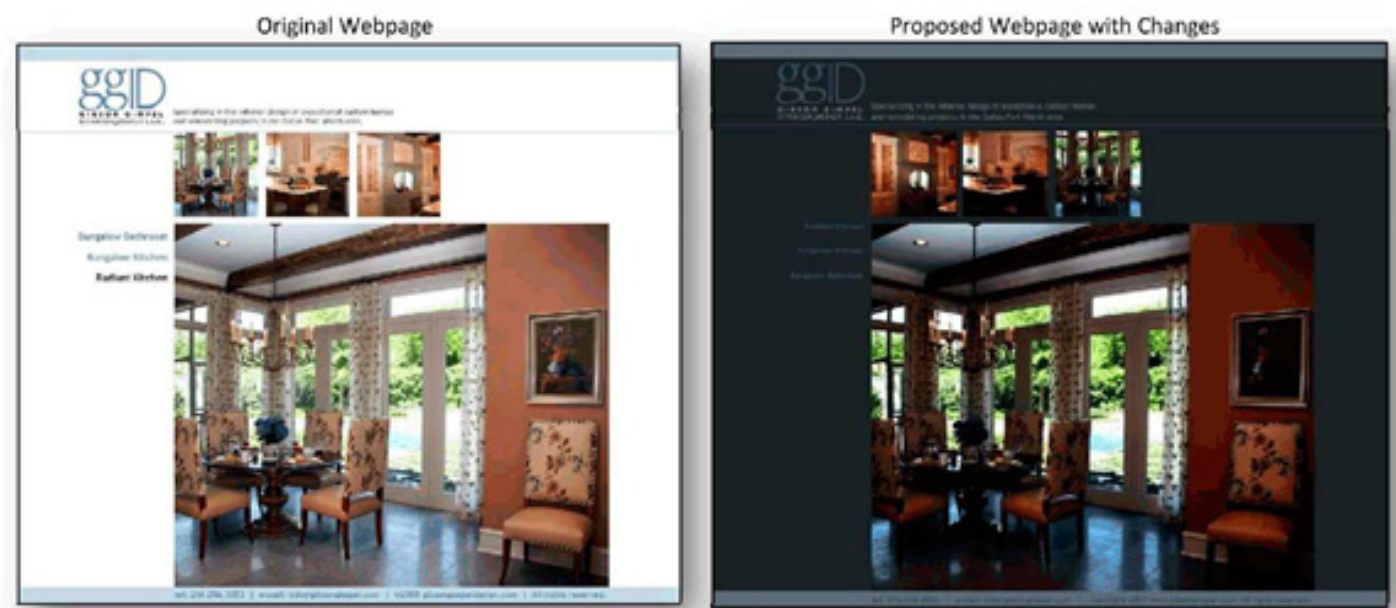

Please indicate your strength of agreement on the 1 to 7 scale below For definitions, please hold the cursor above a radio button for two seconds

1. The visual centrast has changed from the original webpage

Strongly disagree Neutral Strongly agree

2 . The visual emphasis has changed from the original webpage

3. The visual focus has changed from the original webpage

$1 \bigcirc 2 \bigcirc$

${ }_{1} \bigcirc{ }_{2} \mathrm{O}{ }_{3} \mathrm{O}{ }_{4} \mathrm{O}{ }_{5} \mathrm{O}{ }_{6} \mathrm{O}$

${ }_{1} \mathrm{O}_{2} \mathrm{O}{ }_{3} \mathrm{O}{ }_{4} \mathrm{O}{ }_{5} \mathrm{O}{ }_{6} \mathrm{O}{ }_{7} \mathrm{O}$

${ }_{1} \mathrm{O}_{2} \mathrm{O}{ }_{3} \mathrm{O}{ }_{4} \mathrm{O}{ }_{5} \mathrm{O}{ }_{6} \mathrm{O}{ }_{7} \mathrm{O}$

${ }_{1} \mathrm{O}_{2} \mathrm{O}{ }_{3} \mathrm{O}_{4} \mathrm{O}_{5} \mathrm{O}{ }_{6} \mathrm{O}{ }_{7} \mathrm{O}$

${ }_{1} \mathrm{O}_{2} \mathrm{O}{ }_{3} \mathrm{O}{ }_{4} \mathrm{O}{ }_{5} \mathrm{O}{ }_{6} \mathrm{O}{ }_{7} \mathrm{O}$ 

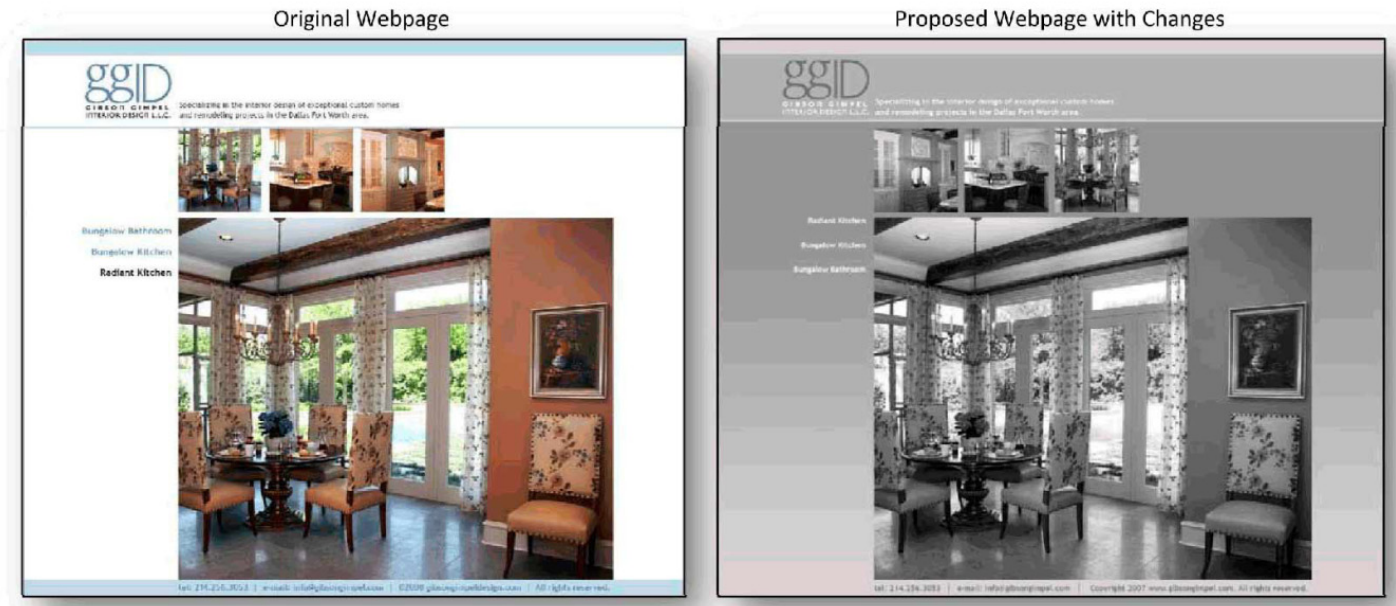

Please indicate your strength of agreement on the 1 to 7 scale below For definitions, please hold the cursor above a radio button for two seconds

1. The visual contrast has changed from the original webpage Strongly disagree Neutral Strongly agree

2. The visual emphasis has changed from the original webpage 3. The visual focus has changed from the original webpage

4. The readability of the type has changed from the original webpage $1 \bigcirc 2$ ${ }^{3} \mathrm{O}^{4} \mathrm{O}^{5} \mathrm{O}{ }^{6} \mathrm{O}{ }^{7} \mathrm{O}$

$1 \bigcirc 2 \bigcirc 3 \bigcirc 4 \bigcirc 5 \bigcirc 6 \bigcirc 70$

$1020{ }_{3} \mathrm{O}_{4} \mathrm{O}{ }_{5} \mathrm{O} 6 \mathrm{O}_{7} \mathrm{O}$ ${ }_{1} \bigcirc 2 \bigcirc 3 \bigcirc 4 \bigcirc 5 \bigcirc 6 \bigcirc 70$ ${ }_{1} \bigcirc 2 \bigcirc 3 \bigcirc 4 \bigcirc 5 \bigcirc 6 \bigcirc 70$

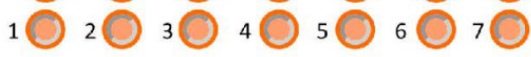


Original Webpage

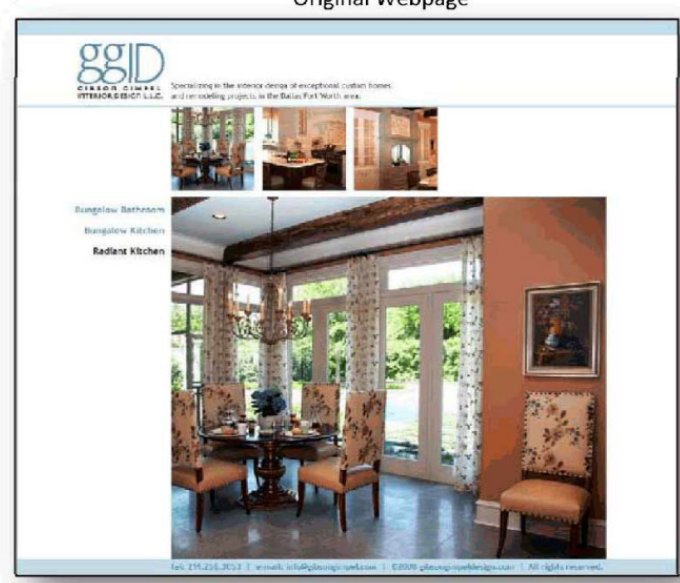

Please indicate your strength of agreement on the 1 to 7 scale below For definitions, please hold the cursor above a radio button for two seconds

1. The visual contrast has changed from the original webpage

2. The visual emphasis has changed from the original webpage

3. The visual focus has changed from the original webpage

4. The readability of the type has changed from the original webpage

5. The visual balance has changed from the original webpage

6. The visual appearance has changed from the original webpage
Proposed Webpage with Changes

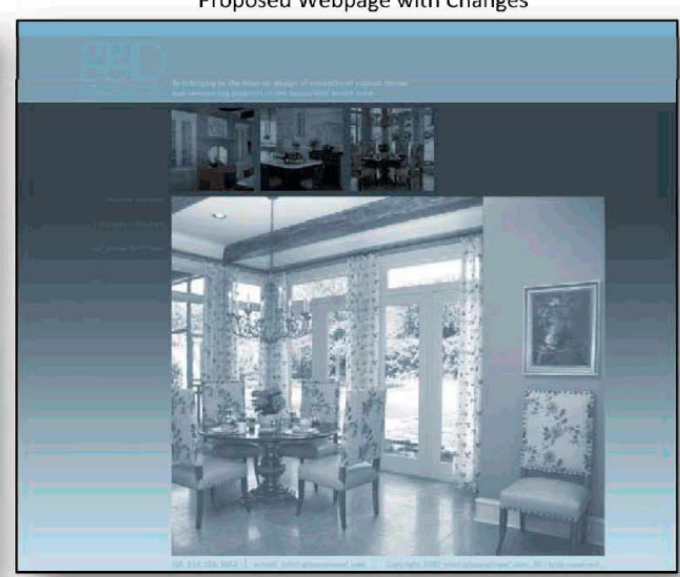

Strongly disagree Neutral Strongly agree

$1 \bigcirc 2 \bigcirc 3 \bigcirc 4 \bigcirc 5 \bigcirc 6 \bigcirc 70$

$1 \bigcirc 2 \bigcirc 3 \bigcirc 4 \bigcirc 5 \bigcirc 6 \bigcirc 7 \bigcirc$

$1 \bigcirc 2 \bigcirc 3 \bigcirc 4 \bigcirc 5 \bigcirc 6 \bigcirc 7 \bigcirc$

$1 \bigcirc 2 \bigcirc 3 \bigcirc 4 \bigcirc 5 \bigcirc 6 \bigcirc 7 \bigcirc$

$1 \bigcirc 2 \bigcirc 3 \bigcirc 4 \bigcirc 5 \bigcirc 6 \bigcirc 7 \bigcirc$

${ }_{1} \bigcirc 2 \bigcirc{ }_{3} \bigcirc{ }_{4} \bigcirc{ }_{5} \bigcirc 6 \bigcirc 7 \bigcirc$ 

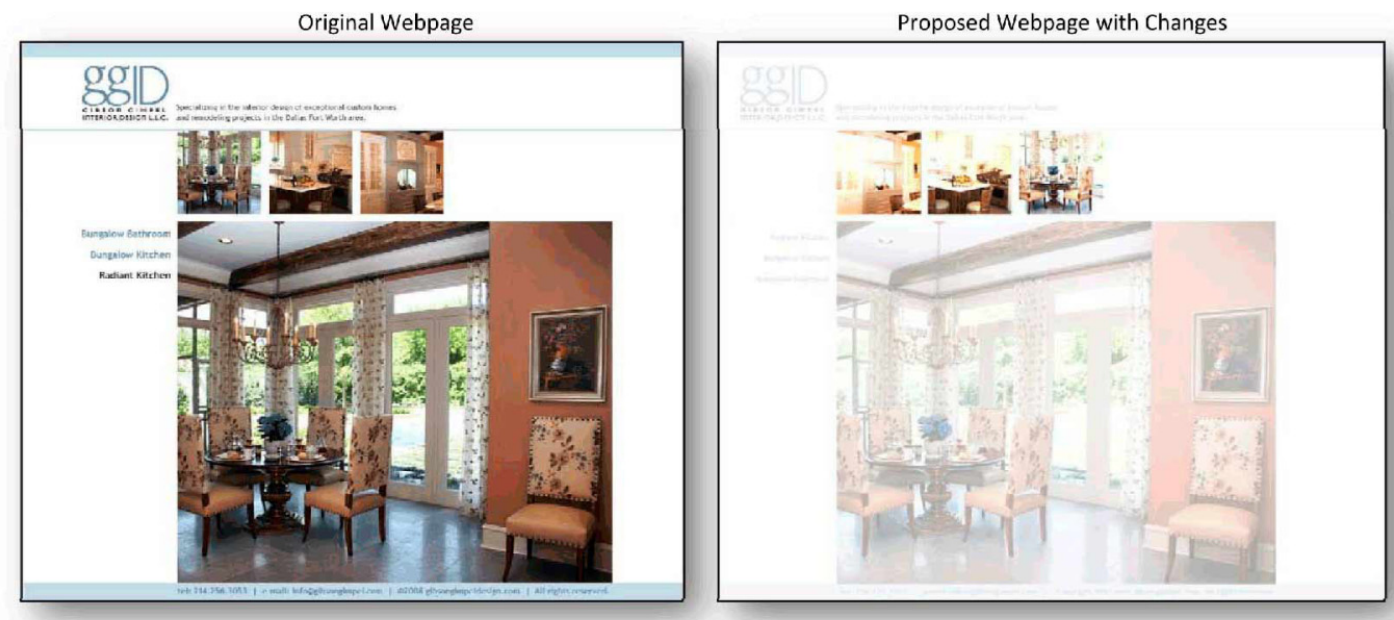

Please indicate your strength of agreement on the 1 to 7 scale below For definitions, please hold the cursor above a radio button for two seconds
1. The visual contrast has changed from the original webpage
2. The visual emphasis has changed from the original webpage 3. The visual focus has changed from the original webpage
4. The readability of the type has changed from the original webpage
5. The visual balance has changed from the original webpage
6. The visual appearance has changed from the original webpage

Strongly disagree Neutral Strongly agree 
Original Webpage

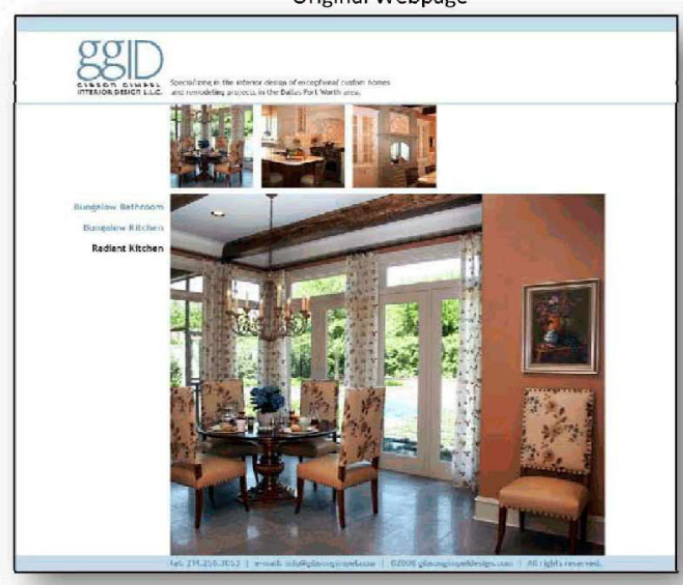

Please indicate your strength of agreement on the 1 to 7 scale below For definitions, please hold the cursor above a radio button for two seconds

1. The visual contrast has changed from the original webpage

2. The visual emphasis has changed from the original webpage

3. The visual focus has changed from the original webpage

4. The readability of the type has changed from the original webpage

5. The visual balance has changed from the original webpage

6. The visual appearance has changed from the original webpage

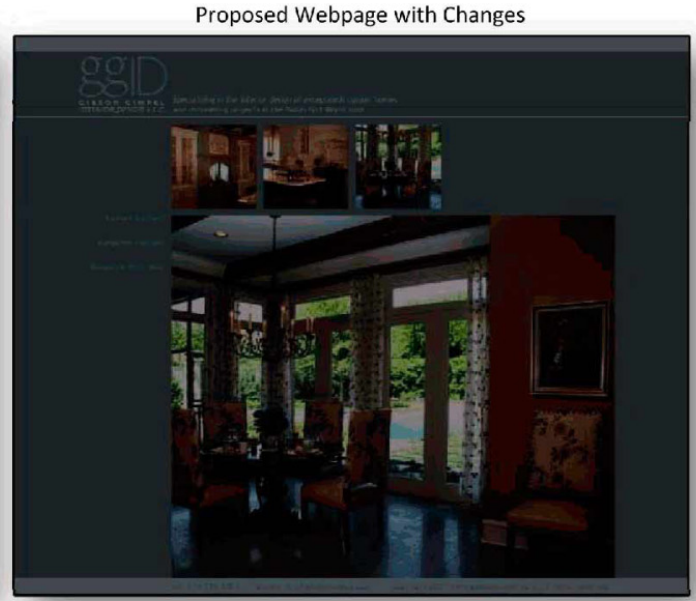

Strongly disagree Neutral

$1 \bigcirc 2 \bigcirc 3 \bigcirc 4 \bigcirc 5 \bigcirc 6 \bigcirc 70$

$1 \bigcirc 2 \bigcirc 3 \bigcirc 4 \bigcirc 5 \bigcirc 6 \bigcirc 70$

$1 \bigcirc 2 \bigcirc 3 \bigcirc 4 \bigcirc 5 \bigcirc 6 \bigcirc 70$

$1 \bigcirc 2 \bigcirc 3 \bigcirc 4 \bigcirc 5 \bigcirc 6 \bigcirc 70$

$1 \bigcirc 2 \bigcirc 3 \bigcirc 4 \bigcirc 5 \bigcirc 6 \bigcirc 70$

${ }_{1} \bigcirc{ }_{2} \bigcirc{ }_{3}{ }_{4} \bigcirc{ }_{5} \bigcirc{ }_{6} \bigcirc 0$ 


\section{Biographies}

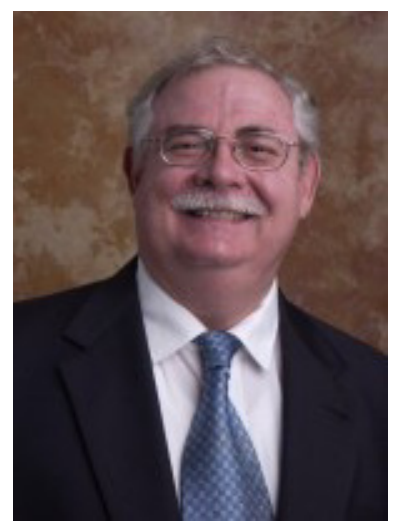

Daniel A. Peak is an associate professor in information technology in the Information Technology and Decision Sciences Department, College of Business Administration at the University of North Texas. He received his Ph.D. in 1994 from UNT with majors in Information Systems and in Finance. He also has several degrees in piano performance, and has studied with well-known pianists and artists. He is an editor of the Journal of IT Cases and Applications Research. Dr. Peak has more than 20 years of IT consulting and planning experience working for executives of Fortune 500 companies, and has won and directed numerous production projects and research grants. He is a member of the Decision Science Institute and Association for Information Systems and has publications in Informing Science, Information and Management, Information Systems Management, and other journals. Dan can be reached by email at daniel.peak@unt.edu

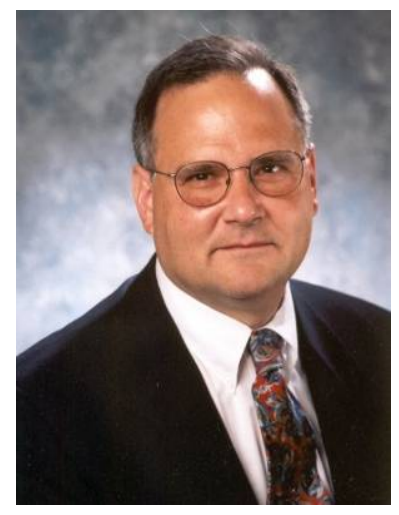

Victor R. Prybutok is a Regents Professor of Decision Sciences in the Information Technology and Decision Sciences Department and Associate Dean of the Toulouse Graduate School at the University of North Texas. He received, from Drexel University, his B.S. with High Honors in 1974, a M.S. in Bio-Mathematics in 1976, a M.S. in Environmental Health in 1980, and a Ph.D. in Environmental Analysis and Applied Sta-tistics in 1984. Dr. Prybutok is an American Society for Quality certified quality engineer, certified quality auditor, certified manager of quality / organizational excellence, and an accredited professional statistician (PSTAT ${ }^{\circledR}$ ) by the American Statistical Association. Dr. Prybutok has authored over 135 journal articles, several book chapters, and more than 150 conference presentations in information systems measurement, quality control, risk assess-ment, and applied statistics. In addition, he serves on the editorial board of the Quality Management Journal. Victor's email is victor.prybutok@unt.edu

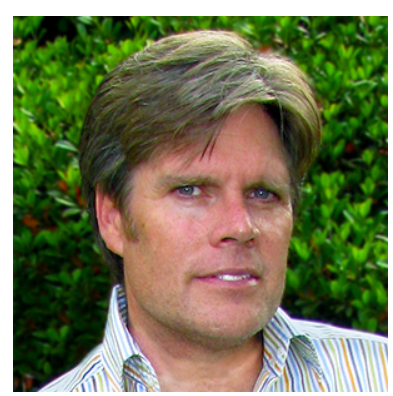

Michael R. Gibson is an Associate Professor of Visual Communication Design and Applied Design Research at the University of North Texas College of Visual Arts and Design (UNT CVAD). He also serves as the coordinator of the graduate programs in Applied Design Research at UNT CVAD, and is a member of National Steering Committee for the Design Educators' Community of the American Institute of Graphic Arts (AIGA). His articles on integrating and teaching others to integrate select design processes with emerging technologies to positively affect the design of complex information systems have appeared in journals such as Visible Language, Information Design Journal, The International Journal of the Humanities, Zed: A Journal of Design Thinking, Design Education in Progress and several others. He has also lectured widely and has operated a private visual and interaction design consultancy for over 20 years. 


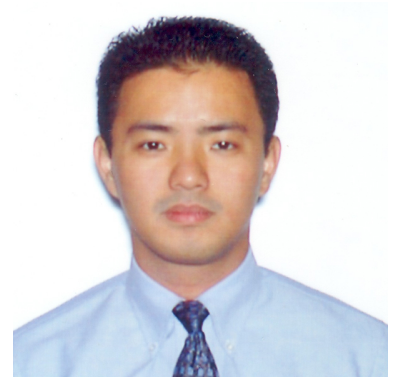

Yu "Andy" Wu is an assistant professor in the Department of Information Technology and Decision Sciences, College of Business at the University of North Texas. He received a Ph.D. (2007) and an M.S. (2003) in Management Information Systems from the University of Central Florida, Orlando, FL. Andy's primary research interests include information security and social networks. His articles appeared in journals such as IEEE Transactions on Professional Communication, Informing Science, Journal of Organizational and End User Computing, Information Resource Management Journal, Business

Process Management Journal, and the proceedings of a number of international conferences. Before his academic career, Andy had seven years' experiences in various technical and business positions.

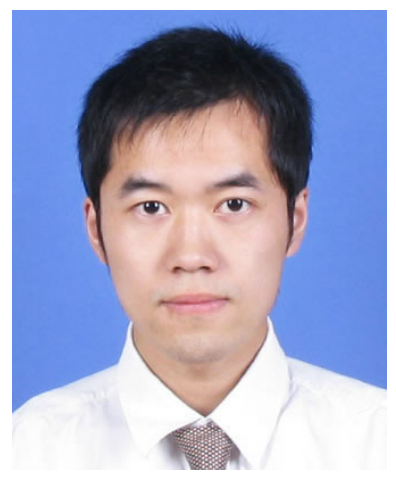

Chenyan Xu is an assistant professor in the Computer Science and Information Systems program, School of Business at the Richard Stockton College of New Jersey. He obtained a Ph.D. in Management Information Systems from the University of North Texas in 2013 and a M.S. in New Media from the Chinese University of Hong Kong. His articles have appeared in journals such as Information and Management, Journal of Computer Information Systems, Informing Science, and Journal of Information Technology Case and Application Research. Prior to his academic career, he was an auditor in Deloitte Touche Tohmatsu C.P.A. Ltd. 